Published in final edited form as:

Ageing Res Rev. 2011 January ; 10(1): 132-145. doi:10.1016/j.arr.2010.09.007.

\title{
Metallothionein and the Biology of Aging
}

\author{
William R. Swindell \\ Department of Genetics, Harvard Medical School, USA, Boston, MA 02115
}

\begin{abstract}
Metallothionein (MT) is a low molecular weight protein with anti-apoptotic properties that has been demonstrated to scavenge free radicals in vitro. MT has not been extensively investigated within the context of aging biology. The purpose of this review, therefore, is to discuss findings on MT that are relevant to basic aging mechanisms and to draw attention to the possible role of MT in pro-longevity interventions. MT is one of just a handful of proteins that, when overexpressed, has been demonstrated to increase mouse lifespan. MT also protects against development of obesity in mice provided a high fat diet as well as diet-induced oxidative stress damage. Abundance of MT is responsive to caloric restriction (CR) and inhibition of the insulin / insulinlike signaling (IIS) pathway, and elevated MT gene expression has been observed in tissues from fasted and CR-fed mice, long-lived dwarf mice, worms maintained under CR conditions, and long-lived daf-2 mutant worms. The dysregulation of MT in these systems is likely to have tissuespecific effects on aging outcomes. Further investigation will therefore be needed to understand how MT contributes to the response of invertebrates and mice to CR and the endocrine mutations studied by aging researchers.
\end{abstract}

\section{Keywords}

caloric restriction; diet; GH; IGF-1; longevity; MTF-1

\section{Introduction}

Caloric restriction (CR) and the inhibition of insulin / insulin-like signals (IIS) have been widely investigated as interventions that delay the onset of age-related disease while promoting an overall increase in both average and maximum lifespan. Understanding the cellular, metabolic and physiological effects of these interventions could point towards clinical tools that foster development of healthy aging patterns in human populations. Additionally, as interventions that affect age-associated diseases in multiple organs, understanding the downstream effects of CR and IIS may provide insights into "mechanisms of aging". Despite extensive investigation, however, there is no firm consensus on why favorable aging outcomes result from either CR or genetic inhibition of IIS (Berryman et al., 2008; Ladiges et al., 2009; Avogaro et al., 2010). One influential idea is that these interventions trigger a type of cell defense response, leading to a cellular phenotype characterized by resistance to multiple forms of stress and the damage associated with normal aging (Masoro and Austad, 1996; Gems and Partridge, 2008; Masoro, 2005; Rattan,

Corresponding Author: William R. Swindell, Harvard Medical School New Research Building, Room 0464, 77 Avenue Louis Pasteur, Boston, MA 02115, wswindel@genetics.med.harvard.edu, Phone: (617) 525-4741, Fax: (617) 525-4705.

Publisher's Disclaimer: This is a PDF file of an unedited manuscript that has been accepted for publication. As a service to our customers we are providing this early version of the manuscript. The manuscript will undergo copyediting, typesetting, and review of the resulting proof before it is published in its final citable form. Please note that during the production process errors may be discovered which could affect the content, and all legal disclaimers that apply to the journal pertain. 
2006). In this view, CR and IIS inhibition induce a "hormesis" response, which could explain some salubrious effects of these interventions (Masoro and Austad, 1996; Masoro, 2005; Rattan, 2006; Gems and Partridge, 2008). A type of hormesis response that has received much attention, in particular, is activation of anti-oxidant defenses, and a number of studies have indeed shown that CR or IIS inhibition can reduce free radical damage (Honda and Honda 1999; Baumeister et al., 2006; Papaconstantinou, 2009; Opalach et al., 2010). Collectively, these ideas have fueled investigation of stress-sensitive pathways and proteins as potential downstream mediators of CR and/or loss of IIS, including heat shock proteins (HSPs), superoxide dismutase (SOD), sirtuins, and stress-regulated polyphenol compounds derived from plants (e.g., resveratrol). At present, however, the most convincing evidence on behalf of these stress-sensitive pathways has been collected from invertebrate systems, and there has been little to suggest that specific activation of a stress-sensitive pathway can generate a long-lived mouse. Worse still, for some of the above-mentioned pathways and proteins, specific activation appears to decrease mouse lifespan, rather than to increase it (Vanhooren et al., 2008).

Metallothionein (MT) is a versatile low molecular weight $(7 \mathrm{kDa})$ protein that participates in the cellular response to numerous forms of stress. In particular, in vitro evidence has suggested that MT can serve as a scavenger of free radicals (Thornalley and Vasák, 1985), which are viewed as a driving force behind multiple age-associated pathologies (Harmon, 1956), as well as a target in the hormesis response associated with CR and/or IIS inhibition. Relative to other stress-sensitive proteins and pathways (e.g., HSPs, SOD and sirtuins), MT has not been aggressively evaluated within the context of aging biology and the study of basic aging mechanisms. Reviews covering potential downstream mechanisms of CR and/or IIS inhibition, for example, have not commonly discussed MT as a target of potential importance (Berryman et al., 2008; Fontana, 2009; Avogaro et al., 2010). In recent years, however, several lines of investigation have engendered compelling evidence that has made MT an attractive target from the standpoint of aging research (Yang et al., 2006; Bahadorani et al., 2010; Sato et al., 2010). For instance, MT belongs to the very small class of proteins for which overexpression has been demonstrated to increase longevity in mice (Yang et al., 2006). Moreover, variation in MT genotypes has been associated with lifespan in humans (Cipriano et al., 2006), and dietary compounds that increase lifespan in mice, flies and worms have been shown to increase MT abundance (Mocchegiani et al., 1998; Kampkötter et al., 2008; Lee et al., 2010; Saul et al., 2010; Sun et al., 2010). MT also plays a protective role against the effects of high fat / high calorie diets (Beattie et al., 1998; Dong et al., 2007; Sato et al., 2010), and much evidence has now shown that MT is induced by CR and IIS inhibition in invertebrate systems and mice (Murphy et al., 2003; Ebadi et al., 2005; BrownBorg, 2006; Szewczyk et al., 2006; Swindell, 2007; Leiser and Miller, 2010; Swindell et al., 2010). MT is also closely connected to stress-sensing pathways and can be induced by harsh environments or noxious substances, and in natural populations, MT gene polymorphisms vary according to environmental stress gradients (Timmermans et al., 2005; Timmermans et al., 2007). Taken together, these properties make MT an appealing research focus from the Biogerontologist's perspective, and appear to naturally connect with the view of CR and IIS as regulators of a conserved stress response, which is aimed at prolonging survival during famine or mounting defense against toxins that may be contained in poorer quality foods consumed when resources are scarce (Masoro and Austad, 1996).

The goal of this review is to present findings on MT relevant to aging biology, with the aim of facilitating further work on MT by those focused on the elucidation of basic aging mechanisms. It will be argued (tacitly or otherwise) that MT requires further investigation within the context of aging biology, and specifically, that further study of MT is needed in relation to its potential role in the cellular response to IIS inhibition and nutrient limitation. Several high-quality reviews on MT and its general properties are available, but many of 
these have centered on toxicological properties of MT, the regulation of MT expression at the molecular level, or the association between MT and one specific type of disease (Andrews, 2001; Eckschlager et al., 2009; Klaassen et al., 2009). This review will therefore focus on key properties of MT that are of special interest to those studying aging mechanisms, with emphasis on results that have emerged from rodent, fly and worm model systems. An overview of MT's properties, transcriptional regulation and postulated role in oxidative stress defense is provided. Additionally, connections between MT and longevity or healthy aging are highlighted, along with potential mechanisms that may explain dysregulation of MT in response to IIS inhibition or CR.

\section{Metallothionein: A quick review (or introduction) for the Biogerontologist}

The cysteine-rich MT protein was first isolated from horse kidney in 1957 and was noted for its remarkable capacity to bind cadmium (Margoshes and Vallee, 1957). The MT metalloprotein is distributed widely within the cell and has been identified within the cytosol, nucleus, lysosome and intermembrane space of mitochondria (Suzuki-Kurasaki et al., 1997; Ye et al., 2001). MT is stabilized by interactions with metal ions ( $\mathrm{Zn}, \mathrm{Cd}, \mathrm{Cu}, \mathrm{Hg}$, $\mathrm{Pb}, \mathrm{Ni}, \mathrm{Co}$ ), and in vivo, binding of MT to metals protects the protein from degradation or excretion. Control of metal ion homeostasis was once thought to be the only function of MT, but acknowledged roles of MT have diversified since its discovery, and MT is now understood to have cytoprotective effects that promote cell survival. In particular, MT is a key component of cellular defenses against oxidative stress and a negative regulator of oxidative stress-mediated apoptosis as well as apoptosis independent of oxidative stress (Dutsch-Wicherek et al., 2008). Additionally, MT buffers tissues against the initiation of inflammatory cascades following injury (Inoue et al., 2009), modulates cell growth and metabolism (Ye et al., 2001; Sato et al., 2010), and within the central nervous system, MT can bolster regenerative capacity following injury by acting as an extracellular activator of signaling pathways (Leung et al., 2010). From a functional standpoint, therefore, critical activities of MT are not limited to metal ion homeostasis, but include the promotion of cellular survival and tissue regeneration, metabolic activity, and the blunting of pathways that promote inflammatory or apoptotic responses (Figure 1).

The human genome includes a large set of MT genes belonging to four families (MT-I, MT-2, MT-3 and MT-4), which collectively encode ten MT isoform proteins. While some functional redundancy may exist among MT genes and proteins in humans, this appears to be less true of the simpler MT gene family in rodent, fly and worm model systems frequently studied by aging biologists. The mouse genome includes only four MT genes (Mt1, Mt2, Mt3 and Mt4) that are located on chromosome 8 (encoding four MT isoforms). Mouse $M t 1$ and $M t 2$ genes are best conserved across species and are widely expressed with a correlated expression pattern across most tissues (Figure 2). The partly shared expression pattern of $M t 1$ and $M t 2$ is distinct from that of most other mouse genes, such that Mt1 and $M t 2$ have few other genes that can be considered as close "neighbors" within the genomewide transcriptional network (Swindell, 2008b). Expression of Mt1 and Mt2 is highest in pancreas, prostate and spinal cord, and weakest in thymocytes and T cells (Figure 2). The expression of mouse $M t 3$ and $M t 4$ is much more limited and tissue-specific. Expression of Mt3 is restricted mostly to the central nervous system, but may also be detected in white adipose tissue and osteoclasts, while expression of $M t 4$ is limited to stratified squamous epithelial tissues within the epidermis and stomach (Figure 2). In the Drosophila genome, four MT genes are present (MtnA, MtnB, MtnC and $M t n D)$, and while all four genes are expressed in the larval or adult gut, only $M t n A$ is highly expressed in most Drosophila body regions (Figure 3). In $C$. elegans, two MT encoding genes have been characterized ( $m$ tl-1 and $m t l-2$ ) and these are expressed in the intestine and pharynx (Moilanen et al., 1999). 
Regulation of $M t 1$ and $M t 2$ in mice has been well-studied and it is clear that, in some contexts, the zinc-regulated metal transcription factor 1 (MTF-1) plays a major role in controlling transcription from the $M t 1$ and $M t 2$ promoters. Expression of MTF- 1 is detectable in most mouse tissues, with greatest expression in the testis and certain components of the visual system (e.g., retina; see Figure 2). The gene encoding MTF-1 is required for proper development and MTF-1-null mice die at embryonic day 13-14 due to liver abnormalities (Wang et al., 2004). However, cells derived from MTF-1-null embryos can survive in culture and this has facilitated the study of how MTF-1 regulates expression of $M t 1, M t 2$ and other target genes. MTF-1-dependent regulation of $M t 1$ and $M t 2$ appears to proceed by a negative feedback loop, in which MTF-1 is activated and induced to enter the nucleus upon binding to intracellular zinc. In the nucleus, MTF-1 binds to the metal response element (MRE) to induce expression of $M t 1$ and $M t 2$ (and other genes), but this entire process is repressed when free levels of intracellular zinc are diminished by newly synthesized MT outside the nucleus. This MT/ MTF-1 regulatory process has been best established within the context of heavy metal stress (Heuchel et al., 1994). However, in many contexts, transcription of $M t 1$ and $M t 2$ in mice is not completely explained by MTF-1 activity and it is likely that a range of factors combine to modulate $M t 1$ and $M t 2$ expression in a context-specific fashion. This multi-factorial regulation is probably reflected by the wide range of stress and non-stress treatments that have been shown to induce expression of Mt1 and Mt2 (Bakka et al., 1982;Sato and Bremner, 1993;Iszard et al., 1995;Satoh et al., 1997; Yang et al., 2009). For instance, the promoter structures of mouse Mt1 and Mt2 are complex and include binding elements for a range of transcription factors, including metal response element (MRE), anti-oxidant response element (AREs), glucocorticoid response element (GRE), and binding sites for signal transducers and activators of transcription (STAT) factors. It is also possible that genomic regions outside of the $M t 1$ and $M t 2$ promoters play a part in regulating transcription of $M t 1$ and $M t 2$ (e.g., see mechanism presented by Frankel et al., 2010). Among invertebrates, regulation of MT genes appears to be partly conserved relative to mice. The Drosophila genome, for example, contains a metal response element-binding transcription Factor-1, which is highly expressed in most tissues (Figure 3) and exhibits approximately 50\% amino acid similarity to mouse MTF-1. In the $C$. elegans genome, however, only two metallothionein genes are present ( $m t l-1$ and $m t l-2)$, and while no transcription factor has strong similarity to the mouse or Drosophila MTF-1, ELT-2 was reported to bind the $m t l-1$ and $m t l-2$ promoters and induce their expression in the C. elegans intestine (Moilanen et al., 1999).

MT is a prototypical stress-response protein and an extensive collection of studies have documented the involvement of MT in response to numerous types of stress, including heavy metal toxicity, alkylating agents, drug toxicity, bacterial endotoxin, viral infection, endoplasmic reticulum (ER) stress and oxidative stress (Bakka et al., 1982; Sato and Bremner, 1993; Iszard et al., 1995; Satoh et al., 1997; Yang et al., 2009). The anti-oxidant role of MT is of special interest in the context of aging biology, although there has been some controversy in this regard, with conflicting results and uncertainty about whether in vitro findings provide insights into the activity of MT in vivo (Sato and Bremner, 1993; Viarengo et al., 2000). In most mouse tissues, $M t 1$ and $M t 2$ are expressed at high levels, and within the central nervous system regions (e.g., cerebellum, hippocampus, hypothalamus),

$M t 1$ and/or $M t 2$ expression is higher than that of catalase, superoxide dismutase, glutathione peroxidase, thioredoxin and methionine sulfoxide reductase A (Figure 2). Likewise, expression of MtnA is higher than other anti-oxidant-encoding genes in most Drosophila larval and adult tissues (Figure 3). Potentially, therefore, any ability of MT to act against free radical species could have widespread impact on redox homeostasis, and indeed, observations from in vitro systems provide strong indication that cysteinyl thiolate groups within the MT protein impart a free radical scavenging capacity. In one influential study, Thornalley and Vašák (1985) studied several MT preparations and estimated the 
biomolecular reaction rate between MT and superoxide or hydroxyl radicals. The estimated rate constant between MT and superoxide radical was comparable to that which had previously been observed for glutathione (Thornalley and Vašák, 1985). However, the estimated rate constant between MT and hydroxyl radical was approximately 300 -fold greater than that associated with glutathione (Thornalley and Vašák, 1985). These observations resonate with those from cell culture studies, which have shown that cells from MT-null mice are sensitive to oxidative stress agents, such as tert-butylhydroperoxide, butenolide toxin and paraquat (Lazo et al., 1995; Yang et al., 2009). Additionally, overexpression of MT isoforms confers in vitro resistance to oxidative stress treatments, including for example, paraquat and butenolide toxin (Bakka et al., 1982; Schwarz et al., 1994; Suzuki et al., 2000; Taylor et al., 2004). The specific role of MT in response to mitochondrial oxidative stress is supported by induction of MT in rotenone-treated cells and by the resistance to rotenone that is conferred by overexpression of MT isoforms (Reinecke et al., 2006; Kadota et al., 2010), as well as the induction of MT by the mitochondrial inhibitor 2,4-dinitrophenol (DNP) in fibroblasts and elevated $\mathrm{H}_{2} \mathrm{O}_{2}$ generation in DNPtreated fibroblasts derived from MT-null mice (Futakawa et al., 2006). Most published in vitro studies support an anti-oxidant role for MT, but it is important to mention that some negative results have been reported. For instance, Loher and Robson (1989) showed that overexpression of MT did not improve the survival of Chinese hamster ovary (CHO) cells following exposure to $\gamma$-irradiation, bleomycin, paraquat or hydrogen peroxide. Negative results were also obtained in the study of Kaina et al. (1990), which showed that MT overexpression did not improve survival of $\mathrm{CHO}$ cells treated with $\gamma$-irradiation or bleomycin. Despite these negative results, the totality of in vitro evidence favors a free radical scavenging capacity of MT, including a protective role in defense against mitochondrial oxidative stress (Reinecke et al., 2006; Kadota et al., 2010).

The anti-oxidant function of MT in vivo has proven more difficult to conclusively establish. On the one hand, in vivo treatment of mice with oxidative stress agents augments MT levels, indicating that MT is tied to regulatory pathways that sense presence of reactive oxygen species or oxidative damage. For instance, hepatic MT is induced by the injection of paraquat and this response is heightened if GSH has been depleted by prior treatment with L-buthionine-SR-sulfoximine (BSO) (Nakagawa et al., 1995; Sato et al., 1995; Nakagawa et al., 1998; Haïdara et al., 1999). It is also noteworthy that pre-treatment of mice with MTinducing metals (e.g., $\mathrm{Zn}, \mathrm{Cu}, \mathrm{Bi}, \mathrm{Co}, \mathrm{Cd}$ and $\mathrm{Hg}$ ) can generate a hormesis response conferring resistance to subsequent in vivo treatment with oxidative stressors. Pre-treatment of mice with metals, for instance, improved survival time in paraquat-injected mice and also promoted heightened MT abundance in the lung, which is a target tissue of paraquat toxicity (Satoh et al., 1992). This type of hormesis effect, however, does not necessarily point to MT as the protective factor, since induction of MT by paraquat or metals is non-specific and likely to involve responses not directly related to oxidative stress or MT (Iszard et al., 1995). Stronger evidence for an in vivo anti-oxidant function of MT has thus come from MT-null mice (lacking functional $M t 1$ and $M t 2$ genes) or MT-transgenic mice that overexpress MT systemically or in particular tissues. MT-null mice are sensitive to oxidative stress agents, including the anti-neoplastic drug cisplatinum, which generates oxidative stress damage in kidney and liver (Satoh et al., 1997; Liu et al., 1998; Satoh et al., 2000). Additionally, as compared to wild-type mice, MT-null mice exhibit significantly greater increases in plasma ALT levels following injection of the mitochondrial inhibitor 2,4-dinitrophenol (DNP), suggesting that MT protects against liver damage arising from oxidative stress generated endogenously by mitochondria in vivo (Futakawa et al., 2006). MT-null mice are also sensitive to the generation of superoxide radicals in cardiac tissue that occurs due to Doxorubicin toxicity, and conversely, mice with cardiac specific overexpression of MT are resistant to oxidative stress damage associated with Doxorubicin (Kang et al., 1997; Sun and Kang, 2002). Interpretation of these studies should be tempered by negative results that have 
also been reported. For instance, an early study found that MT-transgenic mice were not resistant to Doxorubicin toxicity, although this might have been due to insufficient $(<5-$ fold) elevation of MT in cardiac tissue (DiSilvestro et al., 1996). Also, Conrad et al. (2000) treated MT-null and wild type mice with $\gamma$-irradiation and 2-nitropropane, which generate superoxide radicals, but found that MT-null and wild type mice had similar survival times after these treatments were administered, with a similar level of oxidative stress damage to DNA, lipids and proteins. Results from in vivo studies, therefore, have not uniformly supported an anti-oxidant role for MT, although most results are consistent with in vitro data and indicate that MT is a component of cellular defenses against oxidative stress damage.

MT has been viewed as a non-essential protein because, at a young age, MT-null mice exhibit few evident abnormalities when provided a normal diet or when maintained in the absence of an external stress condition (Michalska and Choo, 1993). This phenotype suggests that part of MT's functionality is redundant with that of other proteins (e.g., glutathione), or that compensatory mechanisms are induced in the absence of MT to combat background levels of oxidative stress. It is important to consider, however, that MT-null mice have been predominantly examined at younger ages, and little data has been generated on the aging phenotype of MT-null animals. With increasing age, the cumulative burden of oxidative stress damage is expected to grow, and whereas absence of MT may have few pathological effects at a younger age, more substantial effects may arise at later ages. In particular, MT also negatively regulates inflammation and apoptosis while serving as a regenerative factor in the central nervous system or other organs (Cherian and Kang, 2006; Inoue et al., 2009; Leung et al., 2010), and such functions of MT may be especially important for aging phenotypes (Figure 1).

MT also appears to have "housekeeping functions" that are not are not yet well understood, but which could impact aging outcomes. It has been reported, for instance, that MT binds ATP to form an MT-ATP complex, and under standard conditions, this formation may be instrumental for localization of MT to the mitochondrial intermembrane space, where MT could regulate zinc availability and thus modulate cellular respiration (Jiang et al., 1998; Ye et al., 2001; Maret et al., 2002; Costello et al., 2004; however, see Zangger et al., 2000 for contrary results) (Figure 1). Microarray analyses of MT-null mice also point to the involvement of MT in energy regulation, response to endocrine signals, and control of transcription or translation (Miura and Koizumi, 2005). In both kidney and liver, MT-null mice exhibit altered expression of Atp5a1 (ATP synthase, $\mathrm{H}+$ transporting, mitochondrial F1 complex, alpha subunit 1), a member of the Elovl gene family (elongation of very long chain fatty acids), Prodh (proline dehydrogenase) and Gck (glucokinase) (Miura and Koizumi, 2005 ). In the same organs, expression of Igfbp3 (insulin-like growth factor binding protein 3 ) is elevated in MT-null mice, suggesting downstream effects of MT on pathways impacting IGF signals. In a second array analysis of brain tissue (cortex), expression of genes associated with protein synthesis, RNA splicing, translation initiation factor activity and mitochondrial functions were altered in MT-null mice (Penkowa et al., 2006). Interestingly, within brain tissue, absence of MT led to altered expression of ribosomal protein S6 kinase (Rps6kb1) (Penkowa et al., 2006), a downstream element of the TOR pathway for which a loss of function mutation was recently shown to increase mouse lifespan by $9 \%$ (Selman et al., 2009). Collectively, these properties of MT, and characteristics of MT-null mice, provide hints to suggest that the functional importance of MT is not limited to "stressful" environments, and that MT may indeed influence energy or ATP regulation, metabolism, endocrine signaling and processing of mRNA or peptides. 


\section{Metallothionein and Longevity}

MT can be counted among the very few genes that have been demonstrated to generate a long-lived mouse with transgenic overexpression (Yang et al., 2006). A number of genetic manipulations that increase mouse lifespan have been identified in the last decade, but the majority of these have been loss-of-function "knockout" mutations (Swindell, 2009a). In contrast, there have been very few genes for which a gain-of-function approach has been successfully employed to generate a long-lived mouse (Swindell, 2009a). In the study of Yang et al. (2006), targeted overexpression of MT in cardiac tissue increased mouse lifespan by $14 \%$ on the FVB genetic background. MT-transgenic mice $(n=55)$ survived, on average, 30.1 months, while mice from the FVB control strain $(n=55)$ survived 26.5 months on average. This magnitude of lifespan increase (14\%) is comparable to that associated with overexpression of catalase in mitochondria (Schriner et al., 2005), and exceeds the degree of life-extension associated with several genetic manipulations recently reported to increase lifespan in the laboratory mouse (Swindell, 2009a). In addition to increased lifespan, cardiac-specific overexpression of MT countered changes in cardiomyocyte physiology associated with normal aging. In control mice, Yang et al. (2006) showed that aging slowed myocyte contraction, increased intracellular $\mathrm{Ca}^{2+}$ decay rates and decreased peak shortening amplitude; however, all of these age-associated effects were attenuated in myocytes from older transgenic mice with cardiac-specific MT overexpression. Furthermore, myocytes from MT-transgenic mice exhibited decreased apoptosis with lower generation of superoxide, and it was proposed by Yang et al. (2006) that attenuation of superoxide generation was a key factor underlying longevity in MT-transgenic mice. It will be important to determine whether increased survivorship of MT-transgenic mice can be replicated in future studies, since repeatability of survivorship assays has been a growing concern among Biogerontologists (Ladiges et al., 2009). Nevertheless, longevity of MTtransgenic mice may be the most convincing evidence yet attained in support of the view that activation of a stress response mechanism can bolster longevity in a complex mammalian system (at least with respect to a particular organ, i.e., heart).

It is uncertain, however, whether positive effects of MT on cardiac aging should serve as a "proof-of-concept" that can be generalized to other organ systems or tissues. The "stress resistance paradigm" posits that mechanisms conferring robustness against multiple forms of stress are relevant to aging biology as potential avenues leading towards "healthy aging", often defined as an extension of organismal lifespan. In mammalian systems, however, this view may only be applicable to organs that are largely post-mitotic and not prone to generate neoplastic growths - a caveat that has too often been overlooked in discussions of the connection between stress resistance and longevity. In this regard, cardiac tissue is nearly an ideal domain, since overexpression of a stress resistance protein (e.g., MT) may confer cellular robustness against apoptosis, without any costs associated with the generation of stress-resistant neoplasms (Bergmann et al., 2009). The same intervention, however, could prove deleterious at the systemic level, since MT may contribute to the survival of transformed cells and has indeed been viewed as a potential diagnostic marker of tumor progression (Figure 1; Eckschlager et al., 2009). The circumstance of MT is, potentially, comparable with that of heat shock proteins (HSPs) (Morrow et al., 2010). Ubiquitous overexpression of certain HSPs was shown to increase lifespan in C. elegans and Drosophila (Swindell, 2009c). In mice, however, activation of heat shock factor (HSF) or systemic HSP overexpression is associated with suppression of apoptosis, cancer and decreased lifespan (Dai et al., 2007; Vanhooren et al., 2008). HSPs and their influence on mammalian lifespan thus provide a cautionary example of the detrimental effects that may be associated with widespread overexpression of an anti-apoptotic that confers stress resistance at the cellular level. Moreover, a measured view of the contribution of MT to mammalian aging must consider how MT over-abundance would likely impact zinc availability (Figure 1). In 
particular, overexpression of MT is expected to increase sequestering of zinc ions and thus reduce zinc bioavailability, which could have detrimental effects on cell-mediated immunity and the organism's capacity to mount an effective immune response to infectious agents (Figure 1; Mocchegiani et al., 2004; Mocchegiani et al., 2007). For these reasons, further studies, conducted from the standpoint of Biogerontologists, will be necessary to determine whether findings from Yang et al. (2006) are in fact a substantiation of the "stress resistance paradigm" as applied to a complex mammalian system, or alternatively, a tantalizing result of great interest to cardiologists, but without broad implications that extend beyond the specific context of cardiac tissue.

The potential that altered MT abundance will have tissue-specific effects on aging outcomes is well-illustrated by a recent study that evaluated the influence of ubiquitous and tissuespecific overexpression of MTF-1 in Drosophila (Bahadorani et al., 2010). In Drosophila, the MTF-1 transcription factor is a non-specific inducer of MT gene expression, and MTF-1 overexpression is associated with increased expression of the Drosophila MT genes (MtnA $M t n D$ ) as well as genes that regulate heavy metal transport (e.g., Ctr1B and ZnT35C). Bahadorani et al. (2010) showed that, in Drosophila provided a standard diet, systemic overexpression of MTF-1 had no effect on lifespan. However, overexpression of MTF-1 in hemocytes significantly decreased lifespan, and the opposite effect was observed in the nervous system, with overexpression of MTF-1 leading to significantly increased lifespan. Specifically, when MTF-1 was overexpressed in either motorneurons or the peripheral nervous system, lifespan was increased by approximately $40 \%$ and flies were also resistant to iron and cadmium toxicity (Bahadorani et al., 2010). It is not known whether these effects of MTF-1 are MT-dependent, or instead dependent upon other MTF-1-regulated genes or alterations in zinc metabolism. However, these results suggest that elevated MT levels driven by MTF-1 overexpression can have both favorable and detrimental effects on aging and longevity, depending upon the organ system to which MT overabundance is targeted. It is also interesting to note that MTF-1 overexpression in nervous tissue was sufficient to increase lifespan, since recent studies in mice have highlighted the nervous system as a domain in which anti-apoptotic functions of MT can influence phenotypes related to aging (Ebadi et al., 2005; Hands et al., 2010; Leung et al., 2010). In particular, MT has a neuroprotective role against several forms of brain injury (e.g., cerebral ischemia) and is also able to augment the regenerative capacity of astrocytes (Wakida et al., 2006; Leung et al., 2010). Additionally, transgenic MT overexpression confers resistance to parkinsonism in multiple mouse models of Parkinson's disease (Ebadi et al., 2005), and the overexpression of MT3 in HeLa cells reduced the polyQ toxicity that is associated with Huntington's disease (Hands et al., 2010). Like heart, therefore, the brain and central nervous system may represent a context in which elevated MT abundance can have favorable effects on aging outcomes in a mammalian system.

There is much interest in the development of pharmaceutical compounds that modulate activation of longevity-associated pathways in order to predispose individuals towards healthy aging (Warner et al., 2000; Nadon et al., 2008). The exogenous administration of MT in rodents has previously been used to recapitulate some effects of intracellular MT synthesis, including resistance against oxidative stress or toxic agents (Kiliç and Kutlu 2010), repair following neurological damage (Stankovic et al., 2007), and accelerated healing of burn wounds (Morellini et al., 2008). Otherwise, no pharmacological agents are known to specifically induce endogenous MT synthesis, although dietary zinc intake can be viewed as a non-specific means of elevating MT abundance, since elevation of cellular zinc is expected to activate MTF-1 and trigger MT synthesis. In one study, for instance, mice injected with a strong dose of zinc over four consecutive days exhibited a 500-fold increase in Mt1 and Mt2 expression in liver (Liu et al., 2009). Indeed, zinc supplementation has been viewed as a dietary intervention that promotes healthy aging, and in fact, augmenting dietary 
zinc intake late in life improves survival and increases maximum lifespan in mice (Mocchegiani et al., 1998). This effect on lifespan was demonstrated in a cohort of $50 \mathrm{Balb} /$ c mice, where zinc supplementation of drinking water ( $22 \mathrm{mg} / \mathrm{liter})$ was not initiated until 18 months of age, leading to a $10 \%$ increase in maximum lifespan (Mocchegiani et al., 1998). Zinc supplementation has also been reported to delay thymic atrophy in mice (Mocchegiani et al., 1995), and was shown to increase the lifespan of Drosophila mutants that exhibit a phenotype resembling features of Parkinson's disease (Saini and Schaffner, 2010). Effects of zinc supplementation in these cases may or may not be MT-dependent, but do show that altering the MT/zinc system can influence aging outcomes. Along these lines, it is intriguing to note that other interventions shown to influence lifespan can also affect MT abundance.

For instance, resveratrol increases lifespan of rodents provided a high fat diet, and was also shown to increase MT protein levels by $65 \%$ in the hippocampus of rats following ischemic damage (Yousuf et al., 2009). Other polyphenol compounds have also been found to induce MT abundance, including quercetin and tannic acid, both of which increase $C$. elegans lifespan (Kampkötter et al., 2008; Saul et al., 2010; Sreenivasulu et al., 2010). In Drosophila, moreover, both açai fruit and curcumin have been demonstrated to increase lifespan as well as influence expression of MT genes or abundance of MT protein (Van Erk et al., 2004; Agarwal et al., 2010; Lee et al., 2010; Sun et al., 2010).

\section{Endocrine regulation of metallothionein in long-lived mice and worms}

The first mutations demonstrated to increase longevity in a multicellular organism ( $C$. elegans) remain widely studied today and are known to inhibit the insulin / insulin-like (IIS) signaling pathway (Friedman and Johnson 1988; Kenyon et al., 1993). This pathway was subsequently found to regulate longevity in mammals as well, since Ames dwarf mice lacking GH / IGF-1 in circulation were also found to be long-lived, with absence of IGF-1 signaling in such mice viewed as a condition analogous to loss of IIS through the $C$. elegans DAF-2 receptor (Brown-Borg et al., 1996). In mice, the longevity increase associated with GH/IGF-1 inhibition has been demonstrated on multiple genetic backgrounds, although all these backgrounds have been lab-derived, and thus there remains a legitimate question of whether this endocrine manipulation would be effective in wild mice, which already have reduced IGF-1 levels relative to standard laboratory strains (Miller et al., 2002; Harper et al., 2006a). Nevertheless, inhibition of IIS has been shown, on lab-derived genetic backgrounds, to increase lifespan in worms, flies and mice, and IIS has thus remained a longstanding focus amongst aging biologists. The downstream effectors of this pathway are still under investigation, and it remains unclear why IIS inhibition leads to increased lifespan in either mice or invertebrates. It has been proposed, however, that loss of IIS induces a hormesis response that confers both stress resistance and increased lifespan (Gems and Partridge, 2008), and indeed, genes downstream of the DAF-16 transcription factor (activated in daf-2 mutants) include heat shock proteins (HSPs), catalase and superoxide dismutase (SOD) (Murphy et al., 2003). These stress-sensitive pathways have been extensively investigated as possible mechanisms mediating beneficial effects of IIS inhibition in worms and mice (Walker and Lithgow 2003; Swindell et al., 2009). In fact, however, the $C$. elegans MT genes ( $m t 1-1$ and $m t l-2)$ were also been identified as downstream targets of DAF-16, with altered expression in long-lived daf-2 and age- 1 worms (Barsyte et al., 2001; Murphy et al., 2003), and RNAi knockdown of $m t l-1$ decreased the lifespan of $d a f-2$ mutants by 11.6 $24.2 \%$ (Murphy et al., 2003).

The abundance of MT is elevated in multiple tissues from long-lived dwarf models that lack GH and/or IGF-1 in circulation (Ebadi et al., 2005; Brown-Borg, 2006; Swindell, 2007; Leiser and Miller, 2010; Swindell et al., 2010). It is unclear whether factors that underlie this effect are analogous to those that augment MT levels in C. elegans daf-2 mutants, and it is unknown whether MT contributes to the longevity phenotype associated with loss of GH 
and/or IGF-1. Ebadi et al. (2005) and Brown-Borg (2006) were the first to report that MT protein levels are elevated in liver, heart, kidney and brain striatum of Ames dwarf mice (Brown-Borg, 2006). A subsequent meta-analysis of microarray data revealed that expression of $M t 1$ is elevated in hepatic tissue obtained from multiple long-lived dwarf mouse models, including the Ames, Snell, Little, and GHR-KO dwarf mice (i.e., see Additional File 2 from Swindell, 2007). An RT-PCR investigation later confirmed that Mt1 mRNA levels were elevated in the liver of Snell dwarf mice and also demonstrated that Mt1 expression was increased in brain and heart (Leiser and Miller, 2010). On the one hand, these observations are important because they suggest that MT and its effects on metal homeostasis, free radicals, apoptosis, inflammation, and regenerative capacity of tissues may be regulated by endocrine mechanisms not previously described, and that these mechanisms may relate to one or more of the three main endocrine pathways disrupted in Ames and Snell mice (i.e., GH, prolactin, thyroid stimulating hormone). Additionally, from the standpoint of basic aging research, these observations point to a parallelism between long-lived dwarf mice and long-lived daf-2 worms, which could reflect a common downstream IIS effector that contributes to stress resistance and certain aspects of healthy aging that have been described in GH/IGF-1-deficient mice. It is particularly noteworthy, for example, that expression of Mt1 mRNA levels were reported to be elevated in cardiac tissue of Snell dwarf mice (Leiser and Miller, 2010), since it is already known that cardiac-specific overexpression of MT can augment lifespan in at least one mouse strain (i.e., FVB) (Yang et al., 2006). The elevation of MT abundance in long-lived dwarf mice is of additional importance as a factor that may contribute to in vitro stress resistance properties of skin fibroblast cells derived from dwarf mice (Salmon et al., 2005), as well as the in vivo resistance to paraquat toxicity exhibited by Ames dwarf mice (Bokov et al., 2009). These observations, therefore, appear to blend well with results obtained from $C$. elegans daf-2 mutants, and on the surface, seem consistent with endocrine regulation of MT by IIS in $C$. elegans.

It may, however, be premature to conclude that elevation of MT levels in dwarf mice is mechanistically analogous to the elevated MT expression documented in C. elegans daf- 2 mutants. First, the mechanism by which $m t l-1$ expression is elevated in daf- 2 mutant worms has not yet been worked out, and it hasn't been demonstrated that DAF-16 binds to $m t 1-1$ or $m t 1-2$ promoter regions to influence expression of these genes. Secondly, in C. elegans, the absence of a transcriptional regulator comparable to mammalian MTF-1 complicates comparisons between the two systems. Third, in the Ames and Snell long-lived dwarf mice, multiple endocrine pathways are disrupted, and it is possible that MT expression is influenced by deficiencies in thyroid stimulating hormone (TSH) or prolactin (PRL) and their effects on zinc metabolism (Figure 4). For instance, hyperthyroidism in humans is associated with altered plasma and erythrocyte zinc concentration (Zhang et al., 2004), and in rats, experimental induction of hyperthyroidism by injection of L-thyroxine leads to decreased zinc erythrocyte concentrations (Simsek et al., 1997). Hyperprolactinemic patients have reduced plasma zinc levels and other studies support an inverse and mutual regulatory relationship between PRL and zinc concentration in plasma (Koppelman, 1988; Madureira et al., 1999). These results suggest that TSH and/or PRL can modulate zinc homeostasis, in which case absence of TSH and PRL could lead to dysregulation of MTF-1 as well as perturbed MT gene expression in long-lived Ames or Snell mice (Figure 4).

A specific role of GH/IGF-1 in regulation of MT abundance has not been well studied, but this possibility is supported by the fact that expression of $M t 1$ and $M t 2$ is elevated 4 to 7 fold in hepatic tissue of long-lived GHRKO mice (Swindell, 2007; Swindell et al., 2010). Because GHRKO mice have a narrow endocrine deficiency limited to GH-insensitivity and loss of IGF-1 in circulation, this result cannot be explained by the TSH or PRL endocrine abnormalities present in Ames or Snell mice. Recently, moreover, regulation of $M t 1$ and 
Mt 2 by GH / IGF-1 in kidney was demonstrated by a study in which Ames mice were treated with GH for a six-week period, where this GH-treatment restored normal levels of Mt1 and Mt2 expression (Swindell et al., 2010). Interestingly, this effect of GH-treatment was observed only in ad lib-fed Ames dwarf mice, but not CR-fed Ames dwarf mice (Swindell et al., 2010). This result suggests that loss of GH and/or IGF-1 does indeed promote elevated expression of $M t 1$ and $M t 2$ in long-lived dwarf mice, potentially by triggering conserved pathways that are correspondingly activated in long-lived daf-2 mutants (Figure 4).

However, two key issues remain unclear. First, it is uncertain whether altered MT expression in dwarf mice is a direct or indirect consequence of GH/IGF-1 inhibition. It may be, for instance, that in long-lived dwarf mice, reduced stimulation of the GH and/or IGF-1 receptors at the cellular level leads to blunting of an inhibitory pathway, which ultimately activates transcriptional regulators (not yet identified) to induce MT synthesis in dwarf mice (Figure 4). Alternatively, MT dysregulation in dwarf mice may be an indirect consequence of GH/IGF-1 inhibition, which does not primarily involve cellular pathways emanating from the GH or IGF-1 receptors, but rather involves the systemic influence of GH or IGF-1 on, for example, insulin levels, insulin sensitivity, inflammation, adipose tissue abundance, or adipose-derived endocrine factors (Figure 4). In particular, absence of GH signals in longlived dwarf mice leads to increased adiposity, and leptin derived from adipose tissue can induce MT gene expression (Kondoh et al., 2002). Consistent with this possibility, it has been reported that serum leptin levels are elevated 7-fold in old male Snell dwarf mice (Flurkey et al., 2001). In this scenario, elevated MT in dwarf mice is attributable to loss of GH/IGF-1 signals, but the mechanism is indirect, involving the systemic effects of GH/ IGF-1 on circulating levels of leptin (Figure 4).

The second key issue concerns whether, in dwarf mice, MT regulation may be attributable to GH, IGF-1, or possibly, both GH and IGF-1. This distinction is of conceptual importance for the Biogerontologist, since only pathways downstream of IGF-1 may be comparable to those modulated by the $C$. elegans DAF-16 transcription factor. One possibility is that GH directly regulates $M t 1$ or $M t 2$ expression in an IGF-1-independent fashion (Figure 4). For instance, GH activates the STAT1 and STAT3 transcription factors, and these factors have previously been shown to bind a promoter region 297 base pairs upstream of the $M t 1$ gene (Lee et al., 1999). In long-lived dwarf mice, therefore, absence of GH may regulate $M t 1$ and $M t 2$ gene expression through the effects of GH on STAT factors, independently of IGF-1, in a fashion that doesn't compare well with IIS-regulation of MT in C. elegans daf-2 mutant worms. On the other hand, it was recently shown that expression of $M t 1$ was elevated, very slightly, in renal tissue of long-lived PappA(-/-) mice (Swindell et al., 2010). This observation suggests that expression of at least $M t 1$ may by IGF-1-sensitive, since PappA(-/-) mice exhibit a very narrow endocrine deficiency that, in vivo, appears to involve only a lack of IGF-1 bioavailability within individual tissues (Swindell et al., 2010). Another possibility is that IGF-1 may control MT gene expression by modulating the activity of zinc transporter proteins, such as Liv1 / Slc39a6 (el-Tanani and Green, 1996), in which case IGF-1 may have an influence on MT gene expression mediated by zinc levels and the activity of the MTF-1 transcription factor (Figure 4).

MT elevation in long-lived dwarf mice suggests the possibility of a hormesis-like mechanism that is shared between dwarf mice and daf-2 mutants, which may account for generalized stress resistance properties, resistance to oxidative stress, and possibly even certain aspects of the longevity phenotype. Further investigation, however, is needed to better understand how IIS can influence MT abundance in invertebrate systems (both $C$. elegans and Drosophila), and how disruption of orthologous endocrine pathways may underlie MT dysregulation in dwarf mice. 


\section{Regulation of metallothionein by caloric intake}

Caloric restriction $(\mathrm{CR})$ is a dietary intervention in which total caloric intake is reduced by $30-40 \%$ for a prolonged period of time, while ensuring adequate intake of nutrients and avoidance of malnutrition (Minor et al., 2010). The CR diet appears to positively affect aging biomarkers in humans, and animal studies show that CR attenuates multiple agerelated pathologies, including atherosclerosis, sarcopenia and cataract formation. CR is viewed as a pro-longevity intervention, but it is important to note that effects of CR on lifespan are sensitive to genetic background (Forster et al., 2003; Harper et al., 2006b; Liao et al., 2010). Published reports indicate, for example, that CR does not significantly increase lifespan in DBA mice (Forster et al., 2003), in a number of recombinant inbred strains (Liao et al., 2010), or in wild mice (Harper et al., 2006b). These negative results, moreover, may be an underrepresentation of the true number of laboratory experiments in which CR has failed to increase lifespan in mice, given the potential for bias against publication of negative findings that are not statistically significant (Rockwell et al., 2006; Connor, 2008; Dwan et al., 2008). Nevertheless, much interest remains among Biogerontologists in understanding how $\mathrm{CR}$ influences lifespan, several forms of age-related disease, and arguably, the aging process itself. While many mechanisms have been proposed to explain effects of CR on lifespan, the ability of CR to bolster anti-oxidant defense has often been highlighted (Gems and Partridge, 2008). Additionally, there appears to be mechanistic overlap between CR and GH/IGF-1 inhibition (Bonkowski et al., 2006), and indeed, one well known effect of CR (in rodents) is to reduce circulating levels of GH and/or IGF-1 (Dunn et al., 1997).

Meta-analyses of microarray experiments have found that increased expression of $M t 1$ and $M t 2$ is among the most broadly observed responses to the $\mathrm{CR}$ diet in rodent tissues, affecting a range of organs, including heart, skeletal muscle, colon, cochlea, lung and several regions of the central nervous system (cerebellum, spinal cord, striatum, cortex and hippocampus) (Swindell, 2008a; Swindell, 2008b; Swindell, 2009b). While microarray-based expression measurements are susceptible to various forms of artifact (e.g., cross-hybridization), the repeated observation of a CR-induced elevation of MT expression in many such experiments, performed independently by multiple laboratories, argues against this possibility, suggesting that MT abundance is tied to nutrient intake levels in mice. With respect to liver, for instance, increased expression of $M t 1$ following short and long-term CR in B6C3F1 mice was confirmed using RT-PCR in a previous array analysis (Dhahbi et al., 2004). Additionally, Kondoh et al. (2002) have used a cadmium-binding assay to show that a short-term $(24 \mathrm{hr}$.) fasting period dramatically increases MT protein abundance in liver tissue of ICR, BALB/C and C3H mice, and induction of hepatic MT synthesis by starvation was also confirmed by Sogawa et al. (2003). With regard to mouse liver, therefore, elevated expression of $M t$ genes and increased MT protein following reduction of caloric intake have been demonstrated using both genomic and non-genomic methodologies. Few non-genomic studies have been carried out in other mouse tissues and thus there is greater uncertainty regarding how MT is altered by nutrient intake in non-hepatic tissue. Array data suggest that $M t 1$ and/or Mt2 are increased in most tissues of CR-fed mice, but there is some heterogeneity in this effect among tissues, and inconsistency among multiple studies that have evaluated the same tissue (Swindell, 2008a; Swindell, 2009b). This variability reflects the likelihood that, in mice, effects of CR on MT expression are sensitive to a range of experimental factors, including the degree of CR imposed, the length of time animals were maintained on CR, the age of experimental animals, and the genetic background studied in a given experiment.

The elevation of MT expression or protein abundance by CR may be a conserved response to nutrient limitation across species. Szewczyk et al. (2006), for instance, cultured $C$. 
elegans in a "dietary restriction" chemically defined axenic medium (i.e., $C$. elegans maintenance medium, or CeMM), and evaluated effects of this medium on $C$. elegans growth, reproductive and survival characteristics (as compared to a standard medium with an E. Coli food source). When grown in the CeMM medium, C. elegans exhibited many features associated with restriction of dietary intake, including delayed development, reduced reproductive output and increased lifespan (Szewczyk et al., 2006). A microarray analysis of worms grown in CeMM medium revealed increased expression of the FOXO transcription factor daf-16, as well as a 7-fold elevation of $m t 1-1$ expression and 15 -fold elevation of $m t l-2$ expression (see Table 4 from Szewczyk et al., 2006). The abundance of MT may also be altered by dietary restriction protocols applied to Drosophila. Zid et al. (2009) conducted a microarray study of ad lib flies (maintained on $4 \%$ yeast medium) and dietary restricted flies (maintained on $0.25 \%$ yeast medium), and from both of these groups, performed array hybridizations involving low-translation (fewer than 5 ribosomes per mRNA) and high-translation RNA ( 5 or more ribosomes per mRNA). This analysis identified 201 genes with increased translation under dietary restriction, including the ubiquitously expressed Drosophila MT-encoding gene MtnA (Figure 3). These results suggest that genes encoding invertebrate MT orthologues are transcriptionally up regulated by at least one dietary restriction treatment in worms, and potentially by post-transcriptional mechanisms in Drosophila. Invertebrate systems should therefore provide a powerful tool for better understanding MT response kinetics to nutrient limitation, the upstream factors triggered by nutrient limitation to influence MT levels, and the contribution of MT abundance to the aging phenotypes associated with dietary restriction protocols.

Could dietary induction of MT abundance have an important influence on disease resistance and long-term aging outcomes? In mice, MT appears to play a protective role against the effects of high fat / high calorie diets, and this protection may involve a metabolic component in combination with mechanisms that operate at the local tissue level (Figure 1). This aspect of MT was first suggested by studies of MT-null mice provided a normal diet, which indicated that MT-null mice develop early onset obesity along with hyperleptinemia on a C57BL-129Ola or C57BL/6J background (Beattie et al., 1998). These results were later questioned, however, since it was found that obesity did not arise when the MT-null mutation was maintained on the $129 \mathrm{~Sv}$ genetic background. Such background-dependence is not altogether unusual in this context, since effects of high fat diet are notoriously prone to vary among mouse strains, with certain strains exhibiting responses that are nearly opposite to those observed in others (Shockley et al., 2009). However, on the 129Sv genetic background, it was recently shown that female MT-null mice provided a high fat diet gained more weight than $129 \mathrm{~Sv}$ control mice, with elevated levels of plasma leptin, increased expression of the leptin gene ( $L e p / O b$ ) in adipose tissue, expanded white adipose tissue mass in several depots, and increased WAT adipocyte cell size (Sato et al., 2010). It is unclear why loss of MT sensitized 129Sv mice to diet-induced obesity, but an important factor may have been increased adipocyte expression of Mest (mesoderm specific transcript) in MT-null mice (Sato et al., 2010), which is thought to facilitate the enlargement of adipocytes in high fat-fed mice (Takahashi et al., 2005). Metabolic abnormalities associated with decreased leptin sensitivity may also have contributed to a general decline in body weight homeostasis in MT-null mice (Sato et al., 2010). Tissue-specific protective effects of MT against damage associated with high fat diet may not be limited to adipose tissue alone. Dong et al. (2007), for instance, studied the effects of 5 months high fat diet in standard FVB mice as well as transgenic mice with cardiac-specific overexpression of MT (FVB background). Cardiac-specific overexpression of MT protected against deleterious effects of the high fat diet, including enhanced production of reactive oxygen species in cardiomyocytes, altered cardiomyocyte contractile properties (e.g., peak shortening, duration of relengthening), increased intracellular calcium decay rate of cardiomyocytes, and decreased mitochondrial density of ventricular tissue (Dong et al., 2007). 
A basic question is whether, given a diet low in total calories or a certain component (e.g., fat), comparable mechanisms operate to control MT abundance in the short-term relative to the long-term (Figure 4). Immediate responses to CR diets may overlap with those that arise due to fasting, such as depression of leptin levels, or possibly anxiety responses that develop in mice following withdrawal or reduction of food (e.g., corticosterone release; see Figure 4). $M t 2$ was identified as an immediate early response gene based upon its in vitro induction in PC12 cells after the addition of leptin (Waelput et al., 2000), and the infusion of leptin in vivo increases hepatic MT levels (Kondoh et al., 2002). Additionally, a prolonged period of restraint stress (12 hours) in mice promotes an anxiety response that leads to elevation of corticosterone levels, which results in increased binding activity at the MT glucocorticoid response element and subsequent induction of MT synthesis (Ghoshal et al., 1998;Jacob et al., 1999). Both of these effects, depression of leptin and anxiety-associated corticosterone responses, are likely to develop as a short-term response to food restriction and may contribute to altered MT abundance shortly after initiation of a CR-type diet (Jahng et al., 2007) (Figure 4). To some degree, these short-term responses may persist in the long-term, but would likely attenuate and be dominated by long-term metabolic responses that could also influence MT abundance, such as depression of the GH/IGF-1 endocrine axis, reduction of age-associated inflammation, reduced core body temperature, or loss of adipose tissue mass with decreased secretion of adipose-derived factors (e.g., leptin). The short and longterm responses to low calorie diets are thus likely to involve partially distinct sets of mechanisms that either augment or decrease MT abundance (Figure 4). For these reasons, establishing a detailed time course by which MT levels are altered by restriction of caloric intake will be needed to disentangle mechanisms underlying dietary regulation of MT in vivo.

\section{Summary and Future Directions}

The activation of stress-sensitive pathways may yield protection against cellular damage that accrues during the course of normal aging, and strengthening of stress defenses has been viewed as a means of countering the oxidative stress burden that contributes to senescence. However, as yet, few examples have demonstrated that specific activation of a stresssensitive pathway can favorably influence longevity in a rodent species. Recently, moreover, the free radical theory of aging has itself come under scrutiny, with reports that disruption of anti-oxidant defenses can have no effect on lifespan (Van Remmen et al., 2003; Zhang et al., 2009), or can even increase lifespan (Ran et al., 2007), and that overexpressing anti-oxidant proteins may provide no lifespan gain (Sohal et al., 2006; Jang et al., 2009; Sanz et al., 2010). Amid this torrent of paradigm-challenging results, MT emerges as an attractive target for Biogerontologists seeking to advance an association between stress resistance and longevity, or to re-establish the standing of the free radical theory of aging (Pérez et al., 2009a; 2009b; Salmon et al., 2010). How might MT differ from other antioxidant proteins, which were shown to have no effect on mouse lifespan in survivorship experiments utilizing large sample sizes (e.g., catalase and superoxide dismutase; see reviews by Pérez et al., 2009a; 2009b; Salmon et al., 2010)? Relative to the most well-studied enzymatic antioxidants, MT appears to act against a broader spectrum of free radical species, with an ability to scavenge superoxide, as well as hydroxyl radical, nitric oxide and peroxynitrite (Nielsen et al., 2007). MT might also influence cellular respiration and thus have unique dual influence on both the metabolic generation of free radicals as well as their detoxification (Ye et al., 2001). Importantly, however, critical biological activities of MT may not be limited to its anti-oxidant role (e.g., tissue regeneration, inflammation; see Figure 1). Moreover, attempts to increase mouse lifespan by overexpression of a stress resistance protein may depend on anatomical targeting as much as the specific factor being overexpressed. Many studies failing to support the free radical theory, for example, have involved ubiquitous overexpression of proteins with anti-oxidant activity (Pérez et al., 
2009a; 2009b; Salmon et al., 2010). However, the strongest support for the free radical theory comes from transgenic mice with attenuated forms of cardiac pathology, including mice with cardiac-specific MT overexpression and MCAT mice with overexpression of catalase in mitochondria (Schriner et al., 2005; Yang et al., 2006). In other words, the question of whether the oxidative stress theory is "dead" may depend critically upon which mammalian tissue is under discussion.

Going forward, therefore, a key task will be to identify organ systems for which MT abundance and its anti-apoptotic or regenerative effects might best promote healthy aging outcomes. It has already been demonstrated that MT overexpression in cardiac tissue favorably affects age-associated pathology, but given exciting results from the Drosophila model system (Bahadorani et al., 2010), it will be of special interest to determine whether targeted overexpression of MT in the central nervous system can enhance survival of neuronal populations susceptible to age-associated apoptosis, potentially with positive effects on the preservation of cognitive function with age or overall longevity. It may indeed turn out that such effects of MT are relevant to mechanisms triggered by pro-longevity interventions studied by gerontologists (i.e., IIS inhibition and CR). Studies of invertebrate systems can, along these lines, provide a valuable contribution, since it remains unclear whether $C$. elegans DAF-16 directly interacts with the $m t 1-1$ and $m t l-2$ promoters, and also because Drosophila provides an ideal system for investigating effects of either IIS inhibition or CR on MTF-1 activity. In mice, further work is needed to determine whether MT dysregulation in Ames or Snell mutants is attributable to GH signals, IGF-1 signals, absence of thyroid hormones or prolactin, or to more than one of these endocrine deficiencies, and secondly, to establish whether such endocrine mechanisms are relevant to short or long-term responses of MT to low calorie diets (i.e., fasting or long-term CR). Ultimately, further data may or may not reveal that MT is one of the key "x-factors" underlying longevity phenotypes associated with GH/IGF-1 inhibition or low calorie diets. Regardless, however, the influence of these interventions on MT is likely to impact free radical activity, cumulative oxidative stress burden, apoptotic activity, regenerative capacity of neuronal and possibly other cell types, overall metal homeostasis, and particularly zinc homeostasis with cascading effects on immune system function (Figure 1). An understanding of how MT is regulated by pro-longevity interventions, therefore, is certain to provide at least one component of the "larger picture" that links together the various ways in which these treatments impact individual cells, complex organs, and the emergent functions of multiple organ systems that ultimately determine organismal lifespan.

\section{Acknowledgments}

WRS is supported by NIH grant R01-DK088718-01.

\section{References}

Agarwal R, Goel SK, Behari JR. Detoxification and antioxidant effects of curcumin in rats experimentally exposed to mercury. J Appl Toxicol. 2010; 30:457-68. [PubMed: 20229497]

Andrews GK. Cellular zinc sensors: MTF-1 regulation of gene expression. Biometals. 2001; 14:22337. [PubMed: 11831458]

Avogaro A, de Kreutzenberg SV, Fadini GP. Insulin signaling and life span. Pflugers Arch. 2010; 459:301-14. [PubMed: 19756720]

Bahadorani S, Mukai S, Egli D, Hilliker AJ. Overexpression of metal-responsive transcription factor (MTF-1) in Drosophila melanogaster ameliorates life-span reductions associated with oxidative stress and metal toxicity. Neurobiol Aging. 2010; 31:1215-26. [PubMed: 18775584]

Bakka A, Johnsen AS, Endresen L, Rugstad HE. Radioresistance in cells with high content of metallothionein. Experientia. 1982; 38:381-3. [PubMed: 7075735] 
Barsyte D, Lovejoy DA, Lithgow GJ. Longevity and heavy metal resistance in daf-2 and age-1 longlived mutants of Caenorhabditis elegans. FASEB J. 2001; 15:627-34. [PubMed: 11259381]

Baumeister R, Schaffitzel E, Hertweck M. Endocrine signaling in Caenorhabditis elegans controls stress response and longevity. J Endocrinol. 2006; 190:191-202. [PubMed: 16899554]

Beattie JH, Wood AM, Newman AM, Bremner I, Choo KH, et al. Obesity and hyperleptinemia in metallothionein (-I and -II) null mice. Proc Natl Acad Sci USA. 1998; 95:358-63. [PubMed: 9419380]

Bergmann O, Bhardwaj RD, Bernard S, Zdunek S, Barnabé-Heider F, et al. Evidence for cardiomyocyte renewal in humans. Science. 2009; 324:98-102. [PubMed: 19342590]

Berryman DE, Christiansen JS, Johannsson G, Thorner MO, Kopchick JJ. Role of the GH/IGF-1 axis in lifespan and healthspan: lessons from animal models. Growth Horm IGF Res. 2008; 18:455-71. [PubMed: 18710818]

Bokov AF, Lindsey ML, Khodr C, Sabia MR, Richardson A. Long-lived ames dwarf mice are resistant to chemical stressors. J Gerontol A Biol Sci Med Sci. 2009; 64:819-27. [PubMed: 19414510]

Bonkowski MS, Rocha JS, Masternak MM, Al Regaiey KA, Bartke A. Targeted disruption of growth hormone receptor interferes with the beneficial actions of calorie restriction. Proc Natl Acad Sci USA. 2006; 103:7901-5. [PubMed: 16682650]

Brown-Borg HM. Longevity in mice: is stress resistance a common factor? Age (Dordr). 2006; 28:145-62. [PubMed: 19943136]

Brown-Borg HM, Borg KE, Meliska CJ, Bartke A. Dwarf mice and the ageing process. Nature. 1996; 384:33. [PubMed: 8900272]

Cherian MG, Kang YJ. Metallothionein and liver cell regeneration. Exp Biol Med (Maywood). 2006; 231:138-44. [PubMed: 16446489]

Chintapalli VR, Wang J, Dow JA. Using FlyAtlas to identify better Drosophila melanogaster models of human disease. Nat Genet. 2007; 39:715-20. [PubMed: 17534367]

Cipriano C, Malavolta M, Costarelli L, Giacconi R, Muti E, et al. Polymorphisms in MT1a gene coding region are associated with longevity in Italian Central female population. Biogerontology. 2006; 7:357-65. [PubMed: 16955215]

Connor JT. Positive reasons for publishing negative findings. Am J Gastroenterol. 2008; 103:2181-3. [PubMed: 18671812]

Conrad CC, Grabowski DT, Walter CA, Sabia M, Richardson A. Using MT(-/-) mice to study metallothionein and oxidative stress. Free Radic Biol Med. 2000; 28:447-62. [PubMed: 10699757]

Costello LC, Guan Z, Franklin RB, Feng P. Metallothionein can function as a chaperone for zinc uptake transport into prostate and liver mitochondria. J Inorg Biochem. 2004; 98:664-6. [PubMed: 15041247]

Dai C, Whites ell L, Rogers AB, Lindquist S. Heat shock factor 1 is a powerful multifaceted modifier of carcinogenesis. Cell. 2007; 130:1005-18. [PubMed: 17889646]

Dhahbi JM, Kim HJ, Mote PL, Beaver RJ, Spindler SR. Temporal linkage between the phenotypic and genomic responses to caloric restriction. Proc Natl Acad Sci USA. 2004; 101:5524-9. [PubMed: 15044709]

DiSilvestro RA, Liu J, Klaassen CD. Transgenic mice overexpressing metallothionein are not resistant to adriamycin cardiotoxicity. Res Commun Mol Pathol Pharmacol. 1996; 93:163-70. [PubMed: 8884987]

Dong F, Li Q, Sreejayan N, Nunn JM, Ren J. Metallothionein prevents high-fat diet induced cardiac contractile dysfunction: role of peroxisome proliferator activated receptor gamma coactivator 1alpha and mitochondrial biogenesis. Diabetes. 2007; 56:2201-12. [PubMed: 17575086]

Dunn SE, Kari FW, French J, Leininger JR, Travlos G, et al. Dietary restriction reduces insulin-like growth factor I levels, which modulates apoptosis, cell proliferation, and tumor progression in p53-deficient mice. Cancer Res. 1997; 57:4667-72. [PubMed: 9354418]

Dutsch-Wicherek M, Sikora J, Tomaszewska R. The possible biological role of metallothionein in apoptosis. Front Biosci. 2008; 13:4029-38. [PubMed: 18508497] 
Dwan K, Altman DG, Arnaiz JA, Bloom J, Chan AW, et al. Systematic review of the empirical evidence of study publication bias and outcome reporting bias. PLoS One. 2008; 3:e3081. [PubMed: 18769481]

Ebadi M, Brown-Borg H, El Refaey H, Singh BB, Garrett S, et al. Metallothionein-mediated neuroprotection in genetically engineered mouse models of Parkinson's disease. Brain Res Mol Brain Res. 2005; 134:67-75. [PubMed: 15790531]

Eckschlager T, Adam V, Hrabeta J, Figova K, Kizek R. Metallothioneins and cancer. Curr Protein Pept Sci. 2009; 10:360-75. [PubMed: 19689357]

el-Tanani MK, Green CD. Insulin/IGF-1 modulation of the expression of two estrogen-induced genes in MCF-7 cells. Mol Cell Endocrinol. 1996; 121:29-35. [PubMed: 8865163]

Flurkey K, Papaconstantinou J, Miller RA, Harrison DE. Lifespan extension and delayed immune and collagen aging in mutant mice with defects in growth hormone production. Proc Natl Acad Sci USA. 2001; 98:6736-41. [PubMed: 11371619]

Fontana L. The scientific basis of caloric restriction leading to longer life. Curr Opin Gastroenterol. 2009; 25:144-50. [PubMed: 19262201]

Forster MJ, Morris P, Sohal RS. Genotype and age influence the effect of caloric intake on mortality in mice. FASEB J. 2003; 17:690-2. [PubMed: 12586746]

Frankel N, Davis GK, Vargas D, Wang S, Payre F, et al. Phenotypic robustness conferred by apparently redundant transcriptional enhancers. Nature. 2010; 466:490-3. [PubMed: 20512118]

Friedman DB, Johnson TE. A mutation in the age-1 gene in Caenorhabditis elegans lengthens life and reduces hermaphrodite fertility. Genetics. 1988; 118:75-86. [PubMed: 8608934]

Futakawa N, Kondoh M, Ueda S, Higashimoto M, Takiguchi M, et al. Involvement of oxidative stress in the synthesis of metallothionein induced by mitochondrial inhibitors. Biol Pharm Bull. 2006; 29:2016-20. [PubMed: 17015943]

Gems D, Partridge L. Stress-response hormesis and aging: "that which does not kill us makes us stronger”. Cell Metab. 2008; 7:200-3. [PubMed: 18316025]

Ghoshal K, Wang Y, Sheridan JF, Jacob ST. Metallothionein induction in response to restraint stress Transcriptional control, adaptation to stress, and role of glucocorticoid. J Biol Chem. 1998; 273:27904-10. [PubMed: 9774402]

Haïdara K, Moffatt P, Denizeau F. Metallothionein induction attenuates the effects of glutathione depletors in rat hepatocytes. Toxicol Sci. 1999; 49:297-305. [PubMed: 10416275]

Hands SL, Mason R, Sajjad MU, Giorgini F, Wyttenbach A. Metallothioneins and copper metabolism are candidate therapeutic targets in Huntington's disease. Biochem Soc Trans. 2010; 38:552-8. [PubMed: 20298220]

Harman D. Aging: a theory based on free radical and radiation chemistry. J Gerontol. 1956; 11:298300. [PubMed: 13332224]

Harper JM, Durkee SJ, Dysko RC, Austad SN, Miller RA. Genetic modulation of hormone levels and life span in hybrids between laboratory and wild-derived mice. J Gerontol A Biol Sci Med Sci. 2006a; 61:1019-29. [PubMed: 17077194]

Harper JM, Leathers CW, Austad SN. Does caloric restriction extend life in wild mice? Aging Cell. 2006b; 5:441-9. [PubMed: 17054664]

Heuchel R, Radtke F, Georgiev O, Stark G, Aguet M, et al. The transcription factor MTF-1 is essential for basal and heavy metal-induced metallothionein gene expression. EMBO J. 1994; 13:2870-5. [PubMed: 8026472]

Honda Y, Honda S. The daf-2 gene network for longevity regulates oxidative stress resistance and Mnsuperoxide dismutase gene expression in Caenorhabditis elegans. FASEB J. 1999; 13:1385-93. [PubMed: 10428762]

Inoue K, Takano H, Shimada A, Satoh M. Metallothionein as an anti-inflammatory mediator. Mediators Inflamm. 2009; 2009:101659. [PubMed: 19436762]

Iszard MB, Liu J, Klaassen CD. Effect of several metallothionein inducers on oxidative stress defense mechanisms in rats. Toxicology. 1995; 104:25-33. [PubMed: 8560499]

Jacob ST, Ghoshal K, Sheridan JF. Induction of metallothionein by stress and its molecular mechanisms. Gene Expr. 1999; 7:301-10. [PubMed: 10440231] 
Jahng JW, Kim JG, Kim HJ, Kim BT, Kang DW, et al. Chronic food restriction in young rats results in depression- and anxiety-like behaviors with decreased expression of serotonin reuptake transporter. Brain Res. 2007; 1150:100-7. [PubMed: 17383614]

Jang YC, Pérez VI, Song W, Lustgarten MS, Salmon AB, et al. Overexpression of Mn superoxide dismutase does not increase life span in mice. J Gerontol A Biol Sci Med Sci. 2009; 64:1114-25. [PubMed: 19633237]

Jiang LJ, Maret W, Vallee BL. The ATP-metallothionein complex. Proc Natl Acad Sci USA. 1998; 95:9146-9. [PubMed: 9689048]

Kadota Y, Suzuki S, Ideta S, Fukinbara Y, Kawakami T, et al. Enhanced metallothionein gene expression induced by mitochondrial oxidative stress is reduced in phospholipid hydroperoxide glutathione peroxidase-overexpressed cells. Eur J Pharmacol. 2010; 626:166-70. [PubMed: 19818760]

Kaina B, Lohrer H, Karin M, Herrlich P. Overexpressed human metallothionein IIA gene protects Chinese hamster ovary cells from killing by alkylating agents. Proc Natl Acad Sci USA. 1990; 87:2710-4. [PubMed: 2320583]

Kampkötter A, Timpel C, Zurawski RF, Ruhl S, Chovolou Y, et al. Increase of stress resistance and lifespan of Caenorhabditis elegans by quercetin. Comp Biochem Physiol B Biochem Mol Biol. 2008; 149:314-23. [PubMed: 18024103]

Kang YJ, Chen Y, Yu A, Voss-McCowan M, Epstein PN. Overexpression of metallothionein in the heart of transgenic mice suppresses doxorubicin cardiotoxicity. J Clin Invest. 1997; 100:1501-6. [PubMed: 9294117]

Kenyon C, Chang J, Gensch E, Rudner A, Tabtiang RA. C. elegans mutant that lives twice as long as wild type. Nature. 1993; 366:461-4. [PubMed: 8247153]

Kiliç GA, Kutlu M. Effects of exogenous metallothionein against thallium-induced oxidative stress in rat liver. Food Chem Toxicol. 2010; 48:980-7. [PubMed: 20079794]

Klaassen CD, Liu J, Diwan BA. Metallothionein protection of cadmium toxicity. Toxicol Appl Pharmacol. 2009; 238:215-20. [PubMed: 19362100]

Kondoh M, Tsukahara R, Kuronaga M, Higashimoto M, Takiguchi M, et al. Enhancement of MT synthesis by leptin in fasted mice. Life Sci. 2002; 71:2425-33. [PubMed: 12231403]

Koppelman MC. A potential role for prolactin in zinc homeostasis. Med Hypotheses. 1988:65-8. [PubMed: 3357456]

Ladiges W, Van Remmen H, Strong R, Ikeno Y, Treuting P, et al. Lifespan extension in genetically modified mice. Aging Cell. 2009; 8:346-52. [PubMed: 19485964]

Lattin JE, Schroder K, Su AI, Walker JR, Zhang J, et al. Expression analysis of G Protein-Coupled Receptors in mouse macrophages. Immunome Res. 2008; 4:5. [PubMed: 18442421]

Lazo JS, Kondo Y, Dellapiazza D, Michalska AE, Choo KH, et al. Enhanced sensitivity to oxidative stress in cultured embryonic cells from transgenic mice deficient in metallothionein I and II genes. J Biol Chem. 1995; 270:5506-10. [PubMed: 7890668]

Lee DK, Carrasco J, Hidalgo J, Andrews GK. Identification of a signal transducer and activator of transcription (STAT) binding site in the mouse metallothionein-I promoter involved in interleukin-6-induced gene expression. Biochem J. 1999; 337:59-65. [PubMed: 9854025]

Lee KS, Lee BS, Semnani S, Avanesian A, Um CY, et al. Curcumin Extends Life Span, Improves Health Span, and Modulates the Expression of Age-Associated Aging Genes in Drosophila melanogaster. Rejuvenation Res. 2010 In Press.

Leiser SF, Miller RA. Nrf2 signaling, a mechanism for cellular stress resistance in long-lived mice. Mol Cell Biol. 2010; 30:871-84. [PubMed: 19933842]

Leung YK, Pankhurst M, Dunlop SA, Ray S, Dittmann J, et al. Metallothionein induces a regenerative reactive astrocyte phenotype via JAK/STAT and RhoA signalling pathways. Exp Neurol. 2010; 221:98-106. [PubMed: 19837066]

Liao CY, Rikke BA, Johnson TE, Diaz V, Nelson JF. Genetic variation in the murine lifespan response to dietary restriction: from life extension to life shortening. Aging Cell. 2010; 9:92-5. [PubMed: 19878144]

Liu J, Liu Y, Habeebu SS, Klaassen CD. Metallothionein (MT)-null mice are sensitive to cisplatininduced hepatotoxicity. Toxicol Appl Pharmacol. 1998; 149:24-31. [PubMed: 9512723] 
Liu J, Zhou ZX, Zhang W, Bell MW, Waalkes MP. Changes in hepatic gene expression in response to hepatoprotective levels of zinc. Liver Int. 2009; 29:1222-9. [PubMed: 19490425]

Lohrer H, Robson T. Overexpression of metallothionein in CHO cells and its effect on cell killing by ionizing radiation and alkylating agents. Carcinogenesis. 1989; 10:2279-84. [PubMed: 2480189]

Madureira G, Bloise W, Mendonca BB, Brandão-Neto J. Effect of acute and chronic oral zinc administration in hyperprolactinemic patients. Met Based Drugs. 1999; 6:159-62. [PubMed: 18472906]

Maret W, Heffron G, Hill HA, Djuricic D, Jiang LJ, et al. The ATP/metallothionein interaction: NMR and STM. Biochemistry. 2002; 41:1689-94. [PubMed: 11814364]

Margoshes M, Vallee BL. A cadmium protein from equine kidney cortex. Journal of American Chemical Society. 1957; 79:4813.

Masoro EJ. Overview of caloric restriction and ageing. Mech Ageing Dev. 2005; 126:913-22. [PubMed: 15885745]

Masoro EJ, Austad SN. The evolution of the antiaging action of dietary restriction: a hypothesis. J Gerontol A Biol Sci Med Sci. 1996; 51:B387-91. [PubMed: 8914486]

Michalska AE, Choo KH. Targeting and germ-line transmission of a null mutation at the metallothionein I and II loci in mouse. Proc Natl Acad Sci USA. 1993; 90:8088-92. [PubMed: 8367468]

Miller RA, Harper JM, Dysko RC, Durkee SJ, Austad SN. Longer life spans and delayed maturation in wild-derived mice. Exp Biol Med (Maywood). 2002; 227:500-8. [PubMed: 12094015]

Minor RK, Allard JS, Younts CM, Ward TM, de Cabo R. Dietary interventions to extend life span and health span based on calorie restriction. J Gerontol A Biol Sci Med Sci. 2010; 65:695-703. [PubMed: 20371545]

Miura N, Koizumi S. Gene expression profiles in the liver and kidney of metallothionein-null mice. Biochem Biophys Res Commun. 2005; 332:949-55. [PubMed: 15913548]

Mocchegiani E, Giacconi R, Muti E, Cipriano C, Costarelli L, et al. Zinc-bound metallothioneins and immune plasticity: lessons from very old mice and humans. Immun Ageing. 2007; 4:7. [PubMed: 17903270]

Mocchegiani E, Giacconi R, Muti E, Rogo C, Bracci M, et al. Zinc, immune plasticity, aging, and successful aging: role of metallothionein. Ann N Y Acad Sci. 2004; 1019:127-34. [PubMed: 15247005]

Mocchegiani E, Santarelli L, Muzzioli M, Fabris N. Reversibility of the thymic involution and of agerelated peripheral immune dysfunctions by zinc supplementation in old mice. Int $\mathrm{J}$ Immunopharmacol. 1995; 17:703-18. [PubMed: 8582782]

Mocchegiani E, Santarelli L, Tibaldi A, Muzzioli M, Bulian D, et al. Presence of links between zinc and melatonin during the circadian cycle in old mice: effects on thymic endocrine activity and on the survival. J Neuroimmunol. 1998; 86:111-22. [PubMed: 9663556]

Moilanen LH, Fukushige T, Freedman JH. Regulation of metallothionein gene transcription Identification of upstream regulatory elements and transcription factors responsible for cellspecific expression of the metallothionein genes from Caenorhabditis elegans. J Biol Chem. 1999; 274:29655-65. [PubMed: 10514435]

Morellini NM, Giles NL, Rea S, Adcroft KF, Falder S, et al. Exogenous metallothionein-IIA promotes accelerated healing after a burn wound. Wound Repair Regen. 2008; 16:682-90. [PubMed: 19128263]

Morrow G, Kim HJ, Le Pécheur M, Kaul SC, Wadhwa R, et al. Protection from aging by small chaperones: A trade-off with cancer? Ann N Y Acad Sci. 2010; 1197:67-75. [PubMed: 20536835]

Murphy CT, McCarroll SA, Bargmann CI, Fraser A, Kamath RS, et al. Genes that act downstream of DAF-16 to influence the lifespan of Caenorhabditis elegans. Nature. 2003; 424:277-83. [PubMed: 12845331]

Nadon NL, Strong R, Miller RA, Nelson J, Javors M, et al. Design of aging intervention studies: the NIA interventions testing program. Age (Dordr). 2008; 30:187-99. [PubMed: 19424842]

Nakagawa I, Suzuki M, Imura N, Naganuma A. Involvement of oxidative stress in paraquat-induced metallothionein synthesis under glutathione depletion. Free Radic Biol Med. 1998; 24:1390-5. [PubMed: 9641256] 
Nakagawa I, Suzuki M, Yanagiya T, Imura N, Naganuma A. Effect of glutathione depletion on metallothionein synthesis induced by paraquat in mice. Tohoku J Exp Med. 1995; 177:249-62. [PubMed: 8966720]

Nielsen AE, Bohr A, Penkowa M. The Balance between Life and Death of Cells: Roles of Metallothioneins. Biomark Insights. 2007; 1:99-111. [PubMed: 19690641]

Opalach K, Rangaraju S, Madorsky I, Leeuwenburgh C, Notterpek L. Lifelong calorie restriction alleviates age-related oxidative damage in peripheral nerves. Rejuvenation Res. 2010; 13:65-74. [PubMed: 20230280]

Papaconstantinou J. Insulin/IGF-1 and ROS signaling pathway cross-talk in aging and longevity determination. Mol Cell Endocrinol. 2009; 299:89-100. [PubMed: 19103250]

Penkowa M, Cáceres M, Borup R, Nielsen FC, Poulsen CB, et al. Novel roles for metallothionein-I + II (MT-I + II) in defense responses, neurogenesis, and tissue restoration after traumatic brain injury: insights from global gene expression profiling in wild-type and MT-I + II knockout mice. J Neurosci Res. 2006; 84:1452-74. [PubMed: 16941634]

Pérez VI, Bokov A, Van Remmen H, Mele J, Ran Q, et al. Is the oxidative stress theory of aging dead? Biochim Biophys Acta. 2009a; 1790:1005-14.

Pérez VI, Van Remmen H, Bokov A, Epstein CJ, Vijg J, et al. The overexpression of major antioxidant enzymes does not extend the lifespan of mice. Aging Cell. 2009b; 8:73-5.

Ran Q, Liang H, Ikeno Y, Qi W, Prolla TA, et al. Reduction in glutathione peroxidase 4 increases life span through increased sensitivity to apoptosis. J Gerontol A Biol Sci Med Sci. 2007; 62:932-42. [PubMed: 17895430]

Rattan SI. Hormetic modulation of aging and longevity by mild heat stress. Dose Response. 2006; 3:533-46. [PubMed: 18648625]

Reinecke F, Levanets O, Olivier Y, Louw R, Semete B, et al. Metallothionein isoform 2A expression is inducible and protects against ROS-mediated cell death in rotenone-treated HeLa cells. Biochem J. 2006; 395:405-15. [PubMed: 16402917]

Rockwell S, Kimler BF, Moulder JE. Publishing negative results: the problem of publication bias. Radiat Res. 2006; 165:623-5. [PubMed: 16802861]

Saini N, Schaffner W. Zinc supplement greatly improves the condition of parkin mutant Drosophila. Biol Chem. 2010; 391:513-8. [PubMed: 20302514]

Salmon AB, Murakami S, Bartke A, Kopchick J, Yasumura K, et al. Fibroblast cell lines from young adult mice of long-lived mutant strains are resistant to multiple forms of stress. Am J Physiol Endocrinol Metab. 2005; 289:E23-9. [PubMed: 15701676]

Salmon AB, Richardson A, Pérez VI. Update on the oxidative stress theory of aging: does oxidative stress play a role in aging or healthy aging? Free Radic Biol Med. 2010; 48:642-55. [PubMed: 20036736]

Sanz A, Fernández-Ayala DJ, Stefanatos RK, Jacobs HT. Mitochondrial ROS production correlates with, but does not directly regulate lifespan in Drosophila. Aging (Albany NY). 2010; 2:220-3.

Sato M, Bremner I. Oxygen free radicals and metallothionein. Free Radic Biol Med. 1993; 14:325-37. [PubMed: 8458590]

Sato M, Kawakami T, Kondoh M, Takiguchi M, Kadota Y, et al. Development of high-fat-dietinduced obesity in female metallothionein-null mice. FASEB J. 2010; 24:2375-84. [PubMed: 20219986]

Sato M, Sasaki M, Oguro T, Kuroiwa Y, Yoshida T. Induction of metallothionein synthesis by glutathione depletion after trans- and cis-stilbene oxide administration in rats. Chem Biol Interact. 1995; 98:15-25. [PubMed: 7586048]

Satoh M, Aoki Y, Tohyama C. Protective role of metallothionein in renal toxicity of cisplatinum. Cancer Chemother Pharmacol. 1997; 40:358-62. [PubMed: 9225956]

Satoh M, Naganuma A, Imura N. Effect of preinduction of metallothionein on paraquat toxicity in mice. Arch Toxicol. 1992; 66:145-8. [PubMed: 1605731]

Satoh M, Shimada A, Zhang B, Tohyama C. Renal toxicity caused by cisplatinum in glutathionedepleted metallothionein-null mice. Biochem Pharmacol. 2000; 60:1729-34. [PubMed: 11077056] 
Saul N, Pietsch K, Menzel R, Stürzenbaum SR, Steinberg CE. The longevity effect of tannic acid in Caenorhabditis elegans: Disposable Soma meets hormesis. J Gerontol A Biol Sci Med Sci. 2010; 65:626-35. [PubMed: 20413530]

Schriner SE, Linford NJ, Martin GM, Treuting P, Ogburn CE, et al. Extension of murine life span by overexpression of catalase targeted to mitochondria. Science. 2005; 308:1909-11. [PubMed: 15879174]

Schwarz MA, Lazo JS, Yalowich JC, Reynolds I, Kagan VE, et al. Cytoplasmic metallothionein overexpression protects NIH 3T3 cells from tert-butyl hydroperoxide toxicity. J Biol Chem. 1994; 269:15238-43. [PubMed: 8195159]

Selman C, Tullet JM, Wieser D, Irvine E, Lingard SJ, et al. Ribosomal protein S6 kinase 1 signaling regulates mammalian life span. Science. 2009; 326:140-4. [PubMed: 19797661]

Shockley KR, Witmer D, Burgess-Herbert SL, Paigen B, Churchill GA. Effects of atherogenic diet on hepatic gene expression across mouse strains. Physiol Genomics. 2009; 39:172-82. [PubMed: 19671657]

Simsek G, Andican G, Unal E, Hatemi H, Yigit G, et al. Calcium, magnesium, and zinc status in experimental hyperthyroidism. Biol Trace Elem Res. 1997; 57:131-7. [PubMed: 9282260]

Sogawa N, Sogawa CA, Fukuoka H, Mukubo Y, Yoneyama T, et al. The changes of hepatic metallothionein synthesis and the hepatic damage induced by starvation in mice. Methods Find Exp Clin Pharmacol. 2003; 25:601-6. [PubMed: 14671676]

Sohal RS, Kamzalov S, Sumien N, Ferguson M, Rebrin I, et al. Effect of coenzyme Q10 intake on endogenous coenzyme Q content, mitochondrial electron transport chain, antioxidative defenses, and life span of mice. Free Radic Biol Med. 2006; 40:480-7. [PubMed: 16443163]

Sreenivasulu K, Raghu P, Nair KM. Polyphenol-rich beverages enhance zinc uptake and metallothionein expression in Caco-2 cells. J Food Sci. 2010; 75:H123-8. [PubMed: 20546406]

Stankovic RK, Chung RS, Penkowa M. Metallothioneins I and II: neuroprotective significance during CNS pathology. Int J Biochem Cell Biol. 2007; 39:484-9. [PubMed: 17097331]

Sun X, Kang YJ. Prior increase in metallothionein levels is required to prevent doxorubicin cardiotoxicity. Exp Biol Med (Maywood). 2002; 227:652-7. [PubMed: 12192109]

Sun X, Seeberger J, Alberico T, Wang C, Wheeler CT, et al. Açai palm fruit (Euterpe oleracea Mart.) pulp improves survival of flies on a high fat diet. Exp Gerontol. 2010; 45:243-51. [PubMed: 20080168]

Suzuki Y, Apostolova MD, Cherian MG. Astrocyte cultures from transgenic mice to study the role of metallothionein in cytotoxicity of tert-butyl hydroperoxide. Toxicology. 2000; 145:51-62. [PubMed: 10771131]

Suzuki-Kurasaki M, Okabe M, Kurasaki M. Copper-metallothionein in the kidney of macular mice: a model for Menkes disease. J Histochem Cytochem. 1997; 45:1493-501. [PubMed: 9358851]

Swindell WR. Gene expression profiling of long-lived dwarf mice: longevity-associated genes and relationships with diet, gender and aging. BMC Genomics. 2007; 8:353. [PubMed: 17915019]

Swindell WR. Comparative analysis of microarray data identifies common responses to caloric restriction among mouse tissues. Mech Ageing Dev. 2008a; 129:138-53. [PubMed: 18155270]

Swindell WR. Genes regulated by caloric restriction have unique roles within transcriptional networks. Mech Ageing Dev. 2008b; 129:580-92. [PubMed: 18634819]

Swindell WR. Accelerated failure time models provide a useful statistical framework for aging research. Exp Gerontol. 2009a; 44:190-200. [PubMed: 19007875]

Swindell WR. Genes and gene expression modules associated with caloric restriction and aging in the laboratory mouse. BMC Genomics. 2009b; 10:585. [PubMed: 19968875]

Swindell WR. Heat shock proteins in long-lived worms and mice with insulin/insulin-like signaling mutations. Aging (Albany NY). 2009c; 1:573-7. [PubMed: 20157538]

Swindell WR, Masternak MM, Bartke A. In vivo analysis of gene expression in long-lived mice lacking the pregnancy-associated plasma protein A (PappA) gene. Exp Gerontol. 2010; 45:36674. [PubMed: 20197085]

Swindell WR, Masternak MM, Kopchick JJ, Conover CA, Bartke A, et al. Endocrine regulation of heat shock protein mRNA levels in long-lived dwarf mice. Mech Ageing Dev. 2009; 130:393400. [PubMed: 19428459] 
Szewczyk NJ, Udranszky IA, Kozak E, Sunga J, Kim SK, et al. Delayed development and lifespan extension as features of metabolic lifestyle alteration in C. elegans under dietary restriction. $\mathrm{J}$ Exp Biol. 2006; 209:4129-39. [PubMed: 17023606]

Takahashi M, Kamei Y, Ezaki O. Mest/Peg1 imprinted gene enlarges adipocytes and is a marker of adipocyte size. Am J Physiol Endocrinol Metab. 2005; 288:E117-24. [PubMed: 15353408]

Taylor DM, Minotti S, Agar JN, Durham HD. Overexpression of metallothionein protects cultured motor neurons against oxidative stress, but not mutant $\mathrm{Cu} / \mathrm{Zn}$-superoxide dismutase toxicity. Neurotoxicology. 2004; 25:79-92. [PubMed: 14697883]

Thornalley PJ, Vasák M. Possible role for metallothionein in protection against radiation-induced oxidative stress Kinetics and mechanism of its reaction with superoxide and hydroxyl radicals. Biochim Biophys Acta. 1985; 827:36-44. [PubMed: 2981555]

Timmermans MJ, Ellers J, Roelofs D, van Straalen NM. Metallothionein mRNA expression and cadmium tolerance in metal-stressed and reference populations of the springtail Orchesella cincta. Ecotoxicology. 2005; 14:727-39. [PubMed: 16160751]

Timmermans MJ, Ellers J, Van Straalen NM. Allelic diversity of metallothionein in Orchesella cincta (L.): traces of natural selection by environmental pollution. Heredity. 2007; 98:311-9. [PubMed: 17314922]

Van Erk MJ, Teuling E, Staal YC, Huybers S, Van Bladeren PJ, et al. Time- and dose-dependent effects of curcumin on gene expression in human colon cancer cells. J Carcinog. 2004; 3:8. [PubMed: 15140256]

Van Remmen H, Ikeno Y, Hamilton M, Pahlavani M, Wolf N, et al. Life-long reduction in MnSOD activity results in increased DNA damage and higher incidence of cancer but does not accelerate aging. Physiol Genomics. 2003; 16:29-37. [PubMed: 14679299]

Vanhooren V, Liu XE, Desmyter L, Fan YD, Vanwalleghem L, et al. Over-expression of heat shock protein 70 in mice is associated with growth retardation, tumor formation, and early death. Rejuvenation Res. 2008; 11:1013-20. [PubMed: 19072255]

Viarengo A, Burlando B, Ceratto N, Panfoli I. Antioxidant role of metallothioneins: a comparative overview. Cell Mol Biol (Noisy-le-grand). 2000; 46:407-17. [PubMed: 10774929]

Waelput W, Verhee A, Broekaert D, Eyckerman S, Vandekerckhove J, et al. Identification and expression analysis of leptin-regulated immediate early response and late target genes. Biochem J. 2000; 348:55-61. [PubMed: 10794713]

Wakida K, Morimoto N, Shimazawa M, Hozumi I, Nagase H, et al. Cilostazol reduces ischemic brain damage partly by inducing metallothionein-1 and-2. Brain Res. 2006; 1116:187-93. [PubMed: 16952340]

Walker GA, Lithgow GJ. Lifespan extension in C. elegans by a molecular chaperone dependent upon insulin-like signals. Aging Cell. 2003; 2:131-9. [PubMed: 12882326]

Wang Y, Wimmer U, Lichtlen P, Inderbitzin D, Stieger B, et al. Metal-responsive transcription factor-1 (MTF-1) is essential for embryonic liver development and heavy metal detoxification in the adult liver. FASEB J. 2004; 18:1071-9. [PubMed: 15226267]

Warner HR, Ingram D, Miller RA, Nadon NL, Richardson AG. Program for testing biological interventions to promote healthy aging. Mech Ageing Dev. 2000; 115:199-207. [PubMed: 10906513]

Yang X, Doser TA, Fang CX, Nunn JM, Janardhanan R, et al. Metallothionein prolongs survival and antagonizes senescence-associated cardiomyocyte diastolic dysfunction: role of oxidative stress. FASEB J. 2006; 20:1024-6. [PubMed: 16585059]

Yang HY, Wang YM, Peng SQ. Basal expression of metallothionein suppresses butenolide-induced oxidative stress in liver homogenates in vitro. Toxicon. 2009; 53:246-53. [PubMed: 19084032]

Ye B, Maret W, Vallee BL. Zinc metallothionein imported into liver mitochondria modulates respiration. Proc Natl Acad Sci USA. 2001; 98:2317-22. [PubMed: 11226237]

Yousuf S, Atif F, Ahmad M, Hoda N, Ishrat T, et al. Resveratrol exerts its neuroprotective effect by modulating mitochondrial dysfunctions and associated cell death during cerebral ischemia. Brain Res. 2009; 1250:242-53. [PubMed: 19027723]

Zangger K, Oz G, Armitage IM. Re-evaluation of the binding of ATP to metallothionein. J Biol Chem. 2000; 275:7534-8. [PubMed: 10713058] 
Zhang Y, Ikeno Y, Qi W, Chaudhuri A, Li Y, et al. Mice deficient in both Mn superoxide dismutase and glutathione peroxidase-1 have increased oxidative damage and a greater incidence of pathology but no reduction in longevity. J Gerontol A Biol Sci Med Sci. 2009; 64:1212-20. [PubMed: 19776219]

Zhang F, Liu N, Wang X, Zhu L, Chai Z. Study of trace elements in blood of thyroid disorder subjects before and after 131I therapy. Biol Trace Elem Res. 2004; 97:125-34. [PubMed: 14985623]

Zid BM, Rogers AN, Katewa SD, Vargas MA, Kolipinski MC, et al. 4E-BP extends lifespan upon dietary restriction by enhancing mitochondrial activity in Drosophila. Cell. 2009; 139:149-60. [PubMed: 19804760] 


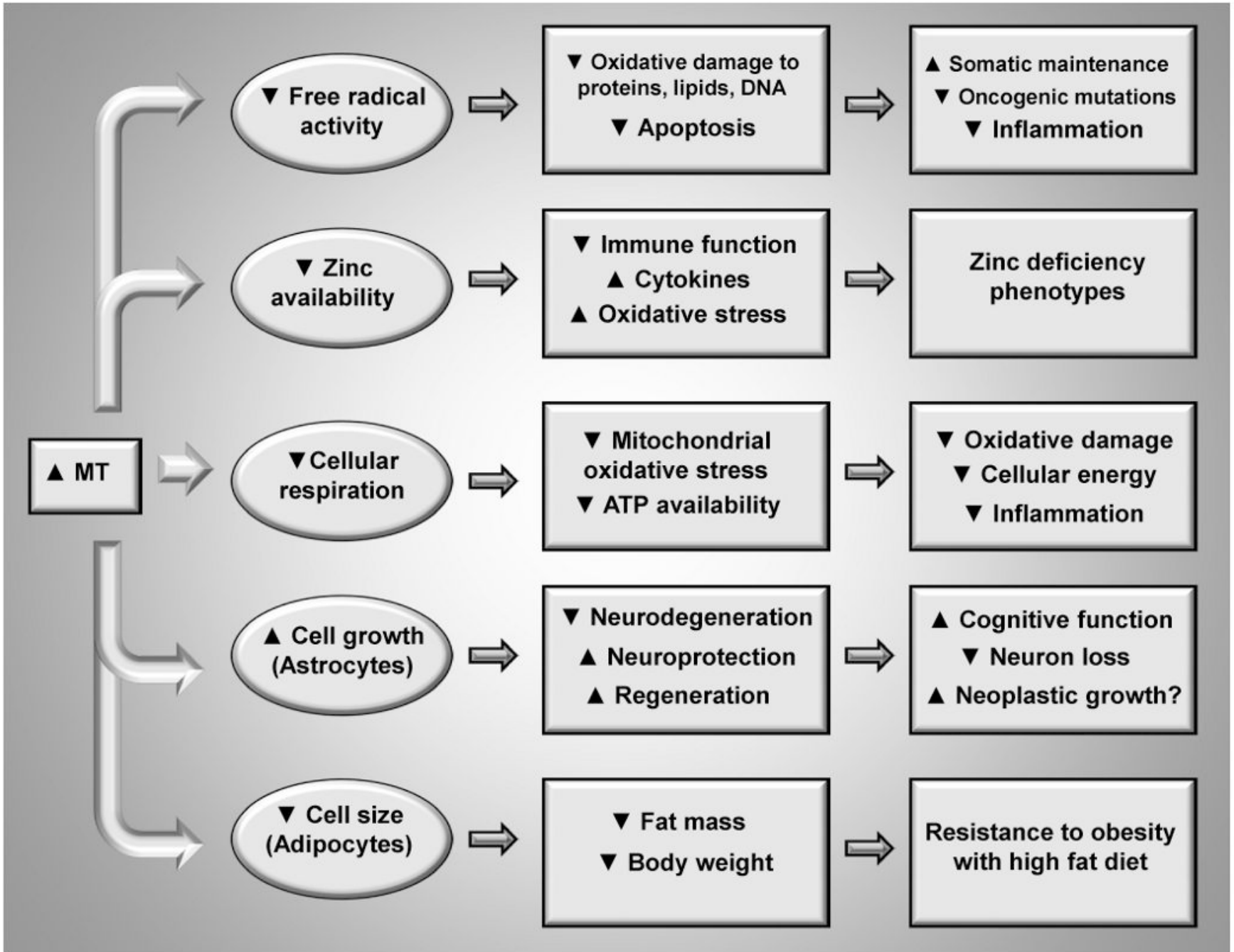

Figure 1. Overview of biological outcomes associated with increased cellular abundance of metallothionein (MT)

Genetic or pharmacological treatments that augment MT abundance have been shown to increase lifespan in model systems (e.g., Mocchegiani et al., 1998; Yang et al., 2006;

Bahadorani et al., 2010), and the expression of MT is dysregulated by endocrine mutations and low-calorie diets that promote longevity in worms, flies and mice (Dhahbi et al., 2004; Ebadi et al., 2005; Brown-Borg, 2006; Szewczyk et al., 2006; Swindell, 2007; Leiser and Miller, 2010; Swindell et al., 2010). The figure provides an overview of several key biological consequences associated with increased abundance of MT. In some cases, consequences of increased MT abundance have been primarily investigated or established within a particular mammalian organ or cell type (i.e., astrocytes and adipocytes), and this has been indicated in the figure where appropriate. 


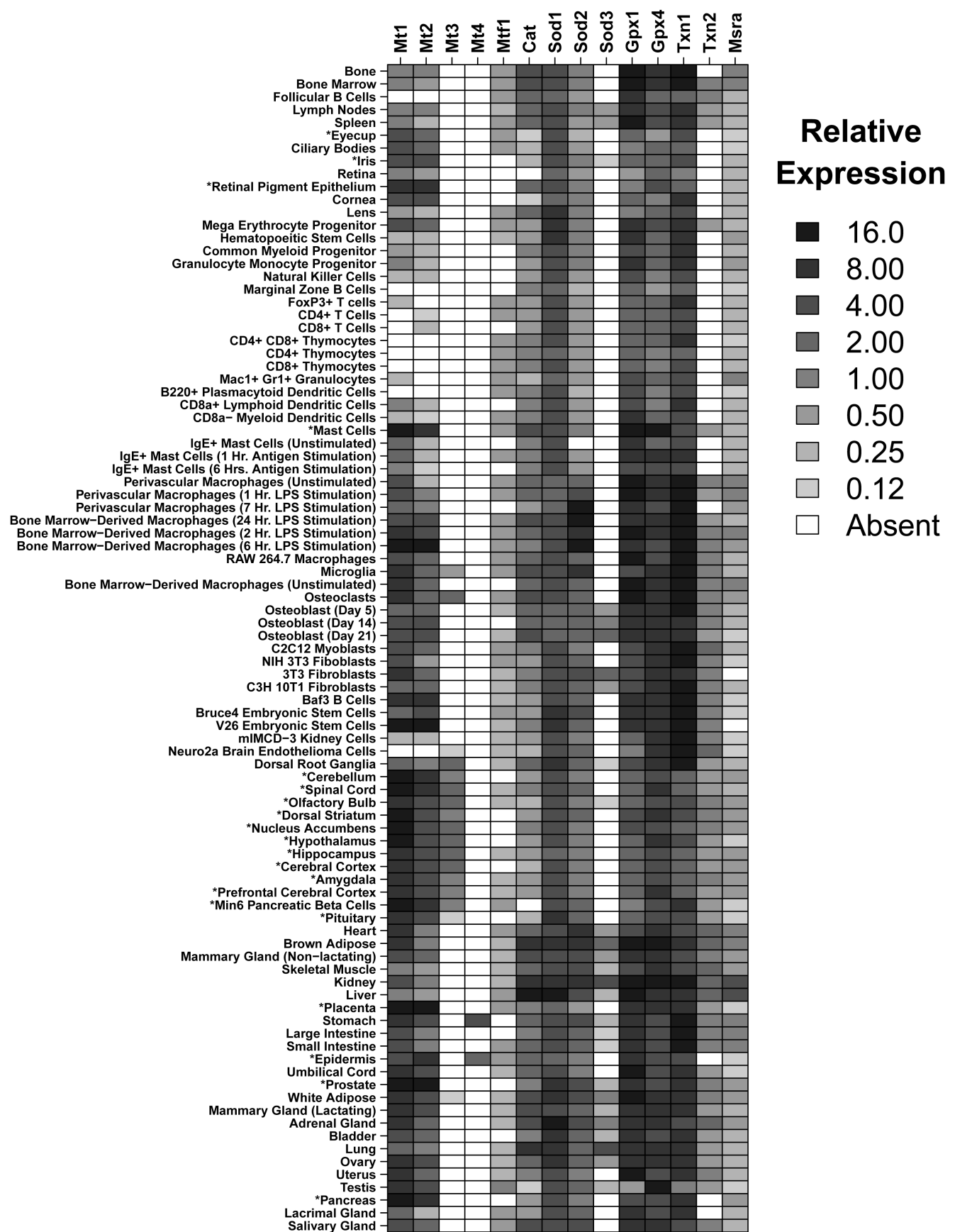

Figure 2. Expression of genes encoding metallothionein (MT) and other proteins with antioxidant activity across mouse tissues

Microarray data generated as part of the Genomics Institute of the Novartis Research Foundation mouse expression atlas (Gene Expression Omnibus series GSE10246) was used to evaluate expression of the metallothionein gene family (i.e., Mt1, Mt2, Mt3, Mt4, Mtf1) across 91 mouse tissues and cell types (Lattin et al., 2008). For comparison, expression levels of other genes encoding proteins with anti-oxidant activity are shown in the figure as well, including catalase (Cat), superoxide dismutase (Sod1, Sod2 and Sod3), glutathione peroxidase ( $G p_{x} 1$ and $\left.G p_{x} 4\right)$, thioredoxin ( $T_{x} n 1$ and $\left.T \times n 2\right)$ and methionine sulfoxide reductase A (Msra) (reviewed by Pérez et al., 2009a; 2009b; Salmon et al., 2010). The 
mouse tissues (rows) have been clustered hierarchically according to similarity of expression patterns across all transcripts represented on the Affymetrix 430 2.0 Mouse Genome array. Expression signals were generated from a batch of 182 Affymetrix microarrays (normalized using the Robust Multichip Average algorithm), where expression values for each tissue represent the average of two biological replicates. The color scale indicates relative expression levels across tissues and genes, where the "Absent" designation is used to identify cases in which a gene was not significantly expressed above background level (based on MAS 5.0 p-value detection calls). The mouse tissues for which expression of either $M t 1$ or $M t 2$ is higher than other genes shown in the figure are indicated by an asterisk symbol (e.g., "*Hippocampus"). The expression signals represented for each gene (column) shown in the figure correspond to a single probe set included on the Affymetrix 4302.0 Mouse Genome array (i.e., 1422557_s_at (Mt1), 1428942_at (Mt2), 1420575_at (Mt3), 1450645_at (Mt4), 1418333_at (MtfI), 1416430_at (Cat), 1451124_at (SodI), 1417193_at $(\operatorname{Sod} 2), 1417633 \_a t(\operatorname{Sod3}), 1460671 \_a t(G p x 1), 1451695 \_a$ at $(G p \times 4), 1416119 \_$at $(T \times n 1)$, 1452782_a_at (TXn2), 1448856_a_at (Msra)). All tissues were obtained from 8 - 10 week old male C57BL6 mice, with the exception of female organs, which were obtained from female C57BL6 mice of the same age (Lattin et al., 2008). 


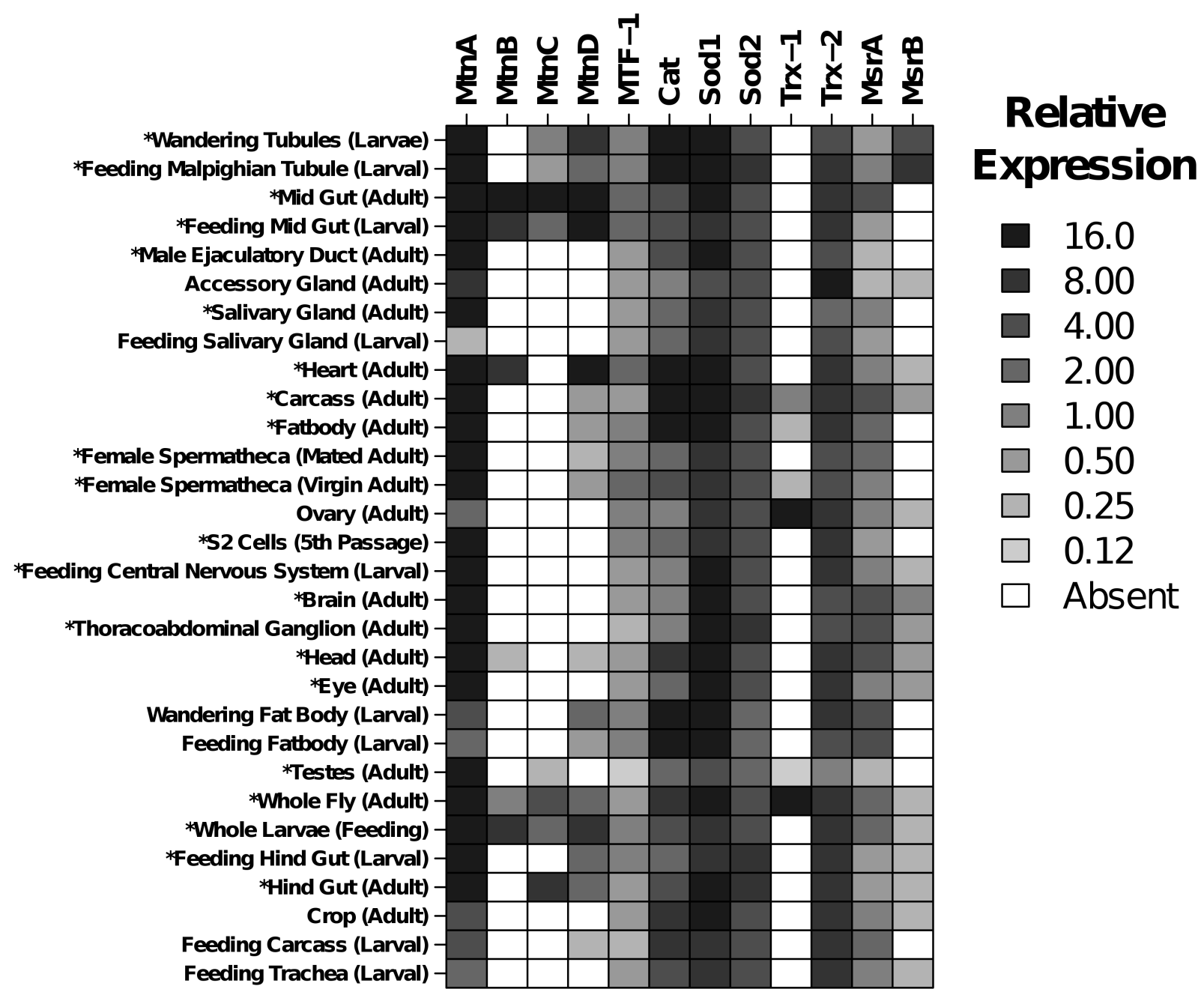

Figure 3. Expression of genes encoding metallothionein (MT) and other proteins with antioxidant activity across Drosophila larval and adult tissues

Microarray data generated by FlyAtlas (Gene Expression Omnibus series GSE7763) was used to evaluate expression of the Drosophila MT family genes (i.e., MtnA, MtnB, MtnC, $M t n D$ and $M T F-1$ ) across 30 cell types or tissues from larvae and adult flies (Chintapalli et al., 2007). For comparison, expression levels of other genes encoding proteins with antioxidant activity are shown in the figure as well, including catalase ( $C a t)$, superoxide

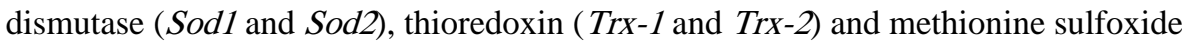
reductase ( $M s r A$ and $M s r B$ ). The adult and larval tissues (rows) have been clustered hierarchically according to similarity of expression patterns across all transcripts represented on the Affymetrix Drosophila Genome 2.0 array. Expression signals were generated from a batch of 120 Affymetrix microarrays (normalized using the Robust Multichip Average algorithm), where expression values for each tissue represent averages from four biological replicates. The color scale indicates relative expression levels across tissues and genes, where the "Absent" designation is used to identify cases in which a gene was not significantly expressed above background level (based on MAS 5.0 p-value detection calls). The fly tissues for which expression of $M t n A$ is higher than other genes shown in the figure are indicated by an asterisk symbol (e.g., "*Brain (Adult)"). The expression signals represented for each gene (column) shown in the figure correspond to a single probe set included on the Affymetrix Drosophila Genome 2.0 array (i.e., 1632873_at (MtnA), 
1630291_at $(M t n B), 1628446 \_a t(M t n C), 1631962 \_$at $(M t n D)$ and 1631619_a_at $(M T F-1)$, 1639480_at $(C a t), 1630845 \_a t(\operatorname{Sod} 1), 1622984 \_$at $(\operatorname{Sod} 2), 1636303 \_$at $(\operatorname{TrX}-1)$,

1629426_s_at $(T r X-2), 1625276 \_a$ at $(M s r A), 1630886 \_$at $\left.(M s r B)\right)$. All adult tissues were obtained from wild-type Canton $\mathrm{S}$ flies (1-week old) that were reared at $22^{\circ} \mathrm{C}$ and maintained on a standard Drosophila diet. 


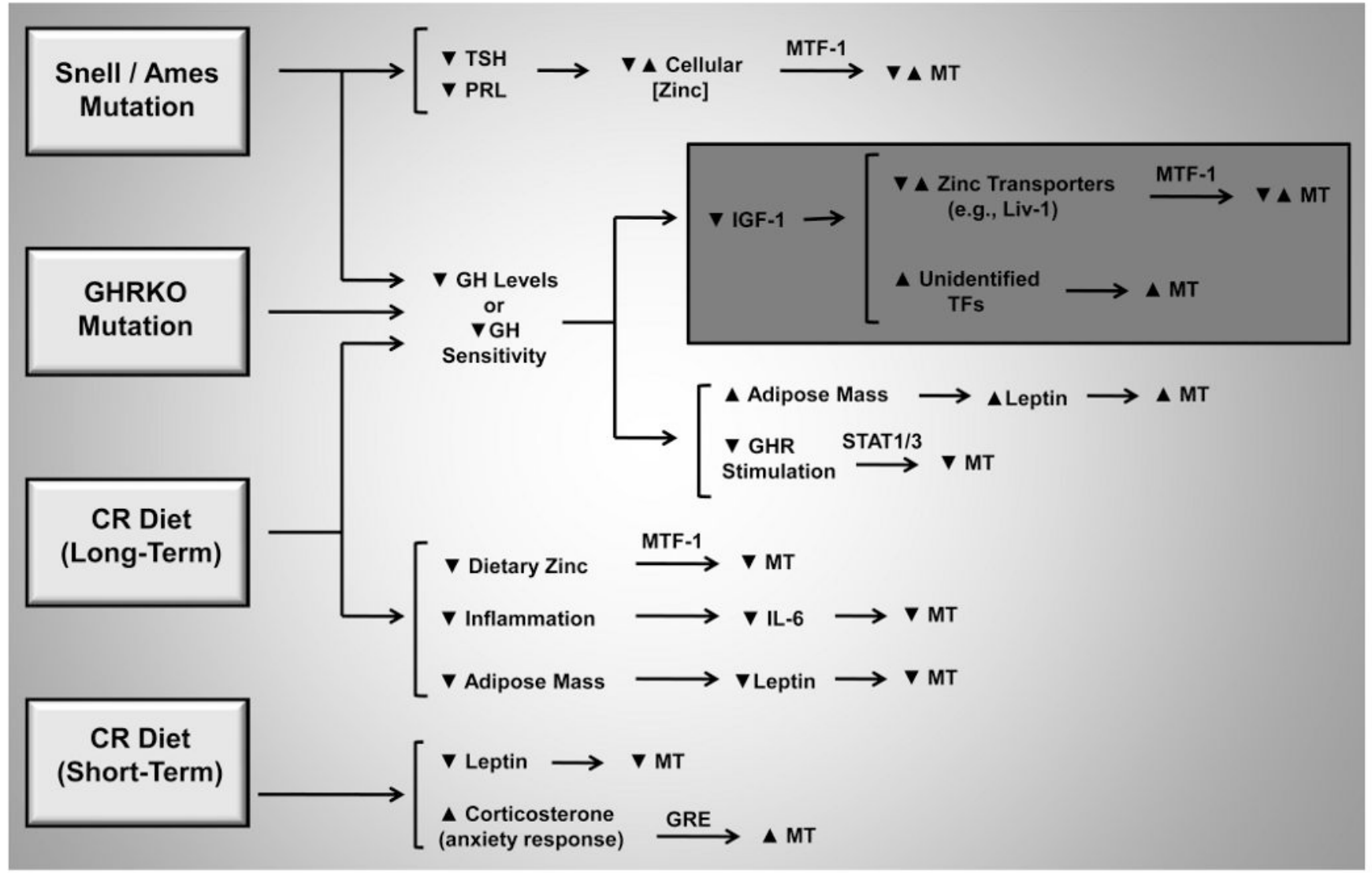

Figure 4. Potential mechanisms contributing to MT dysregulation in long-lived dwarf mice and CR-fed mice

The expression and abundance of MT is altered in long-lived dwarf mice and is also sensitive to short and long-term reduction of caloric intake (see text). Dwarf mutations and $\mathrm{CR} /$ fasting are known to modulate endocrine and intracellular pathways in ways that can have either positive or inhibitory effects on MT abundance. The figure outlines several of these potential mechanisms, including those expected to decrease MT levels as well as those expected to increase MT levels. Potentially, dwarf mutations and/or CR modulate MT levels through more than one mechanism described in the figure, with the cumulative effect on MT levels arising from a shift in the balance between positive and inhibitory mechanisms. Up triangles $(\boldsymbol{\Delta})$ are used to denote effects that involve increased abundance of a particular protein or activation of a pathway, while down triangles $(\boldsymbol{\nabla})$ denote effects that involve decreased abundance of a protein or inhibitory effects. Both up and down triangles are used, in some cases, to indicate uncertainty in the direction of effect. The dark gray box outlines mechanisms that are IGF-1-dependent in mice, which potentially, are comparable to those influencing MT abundance in daf-2 worms. (Abbreviations: $\mathrm{GH}=$ growth hormone; GHR = growth hormone receptor; GHRKO = growth hormone receptor knockout mutation; GRE = glucocorticoid response element; IGF-1 = insulin-like growth factor 1; IL = interleukin; MTF-1 = metal transcription factor $1 ; \mathrm{PRL}=$ prolactin; $\mathrm{STAT}=$ signal transducer and activator of transcription; $\mathrm{TF}=$ transcription factor; $\mathrm{TSH}=$ thyroid stimulating hormone) 